\title{
Discovering pathways in benign prostate hyperplasia: A functional genomics pilot study
}

\author{
ZHELING CHEN $^{1}$ and MINYAO GE ${ }^{2}$ \\ ${ }^{1}$ Department of Traditional Chinese Medicine, Zhenxin Community Health Service Center, Shanghai 201824; \\ ${ }^{2}$ Department of Urology Surgery, Shuguang Hospital Affiliated to Shanghai University of Traditional Chinese Medicine, \\ Shanghai 201203, P.R. China
}

Received February 24, 2020; Accepted October 13, 2020

DOI: $10.3892 /$ etm.2021.9673

\begin{abstract}
Benign prostate hyperplasia (BPH) is one of the well-known urological neoplasms common in males with an increasing number of associated deaths in aging males. It causes uncomfortable urinary symptoms, including urine flow blockage, and may cause bladder, urinary tract or kidney problems. The histopathological and clinical knowledge regarding $\mathrm{BPH}$ is limited. In the present study, an in silico approach was applied that uses genome-scale microarray expression data to discover a wide range of protein-protein interactions in addition to focusing on specific genes responsible for BPH to develop prognostic biomarkers. Various genes that were differentially expressed in BPH were identified. Gene and functional annotation clusters were determined and an interaction analysis with disease phenotypes of BPH was performed, as well as an RNA tissue specificity analysis. Furthermore, a molecular docking study of certain short-listed gene biomarkers, namely anterior gradient 2 (AGR2; PDB ID: 2LNT), steroid 5 $\alpha$-reductase 2 (PDB ID: 6OQX), zinc finger protein 3 (PDB ID: 5T00) and collagen type XII $\alpha 1$ chain (PDB ID: $1 \mathrm{U} 5 \mathrm{M}$ ), was performed in order to identify alternative Chinese herbal agents for the treatment of BPH. Data from the present study revealed that AGR2 receptor (PDB ID: 2LNT) and berberine (Huang Bo) form the most stable complex and therefore may be assessed in further pharmacological studies for the treatment of BPH.
\end{abstract}

\section{Introduction}

Benign prostate hyperplasia (BPH), also known as prostate gland enlargement, is a genitourinary condition that is most

Correspondence to: Dr Minyao Ge, Department of Urology Surgery, Shuguang Hospital Affiliated to Shanghai University of Traditional Chinese Medicine, 528 Zhangheng Road, Shanghai 201203, P.R. China

E-mail: billgmy@shutcm.edu.cn

Key words: benign prostate hyperplasia, gene expression analysis, drug interaction prevalent in aging males, usually starting at 50-61 years of age (1), and causing lower urinary tract symptoms (LUTS), such as urine flow blockage as a result of the urethra being compressed by the enlarged gland. Other potential complications may include bladder, urinary tract or kidney problems (2). Most males have continued prostate growth throughout their life (2) After the age of 30 years, males exhibit a 1\% drop in testosterone production per year and an increase in the level of dihydrotestosterone, possibly due to the age-related increase in $5 \alpha$ reductase (SRD5A2) activity. This rising level of dihydrotestosterone appears to increase prostate cell longevity and proliferation, leading to BPH (3).

$\mathrm{BPH}$ is a histological diagnosis that is specified by non-malignant hyperplasia of the stromal and glandular epithelial cells of the prostate, leading to an enlargement in its size (4). Studies and meta-analyses have revealed that BPH is associated with an increased risk of prostate and bladder cancers (5) due to their common pathophysiological driving factors (6). BPH arises mostly from the peripheral zone (70\%), followed by growth in the transition zone $(20 \%)$ and in the central zone $(10 \%)$ of the gland. The public health burden of $\mathrm{BPH}$ is high due to the increased associated morbidity and treatment costs: As many as 33\% of males older than 50 years, $\sim 50 \%$ of those $>60$ years, $70 \%$ of those $>70$ years and $90 \%$ of those $>85$ years develop BPH (7). The risk for progressing into a cancerous state is small, but instead, the entire prostate gland grows uniformly, with small smooth, elastic and firm hyperplastic nodules. Common complications include urinary tract infections, bladder stones and chronic kidney problems (8). The symptoms maybe obstructive (weakened urine stream, strained or prolonged voiding, urinary hesitancy) or irritative (pain, nocturia, urge incontinence), or may produce a constant sense of incomplete bladder emptying after micturition that leads to the requirement of frequent urination (9).

The primary risk factors for BPH include age, family history, obesity and being of Afro-Caribbean descent. BPH is most common in western countries and affects $>1$ billion males all over the world (6). According to GLOBOCAN estimates, 1.2 million novel cases of prostate cancer were reported worldwide in 2018 (10). Diagnostic methods include physical and digital rectal examinations, prostate-specific antigen (PSA) level measurements, prostate biopsy, prostate ultrasound, urinalysis and urine culture $(11,12)$. PSA, a 
glycoprotein enzyme produced by the epithelial cells of the prostate gland, is considered the mainstay for BPH prognosis and diagnosis. However, it is difficult to differentiate between the increase in PSA levels due to BPH and prostate cancer. Furthermore, the test fails to discriminate between low-risk and aggressive tumors (13). Major invasive and medical therapies are available for BPH treatment (14). Invasive therapies include microwave thermotherapy, prostate needle ablation, as well as surgical, laser and transurethral therapies; medical therapies include a-adrenergic blockers, 5a-reductase inhibitors, phosphodiesterase type-5 inhibitor therapy for BPH/LUTS and b-3-agonist therapy. Pharmaceutical treatments include finasteride (5-alpha reductase inhibitor) and alpha-1 antagonists. Finasteride shrinks the prostate gland by inhibiting the conversion of testosterone into dihydrotestosterone, resulting in urine flow obstruction relief (15), and alpha-1 antagonists (such as phenoxybenzamine) bind alpha-1 receptors of bladder-neck smooth muscle, causing its relaxation and allowing urine to pass (16).

The discovery of genomic mutations and development of high-throughput screening and microarray technologies have opened up possibilities for identifying gene biomarkers for the diagnosis, prognosis and treatment of BPH (17). Genomic functional networks may help reveal interactions between BPH-associated modules, genitourinary diseases and hyperglycemia, and identify pathway-specific interactions. Furthermore, as only a few drugs (with numerous side effects) are available for treating BPH (18), alternative drugs are required. Histopathology methods for BPH remain incomplete. Differentially expressed genes (DEGs) in BPH and normal prostate tissues are likely to reflect underlying pathogenic mechanisms involved in the development of the disease. Complementary DNA microarray technology may be used to identify genes associated with BPH. The present study focused on a specific set of genes responsible for $\mathrm{BPH}$ and performed protein-protein interaction analyses to disclose functional networks. Potential prognostic biomarkers were identified using in silico approaches, high-throughput microarray data and comprehensive protein-protein interaction analyses.

The objectives of the present study were to discover genes that are differentially expressed in BPH and normal prostate tissues, identify functional networks and look for potential alternative BPH agents in a list of Chinese herbs.

\section{Patients and methods}

Datasets. The gene expression profiles of BPH patients from the Gene Expression Omnibus (GEO; https://www.ncbi.nlm. nih.gov/geo/) dataset with the accession number GSE6099 were used. For the analysis, seven samples were selected: A total of four human epithelium samples of BPH nodules (EPI_BPH) and three samples from human epithelium of individuals without a history of prostate disease (EPI_NOR). The epithelium is one of the basic types of animal tissue that lines the outer surface of the prostate gland. The pathological evidence for prostate diseases confirmed the neoplastic changes of the prostate epithelium.

Identification of DEGs. TheGEO2R web-based tool was used for basic processing, analysis of gene expression datasets and identification of DEGs in BPH. The GEO2R tool uses GEO query (19) and the R limma package (20) from the Bioconductor project (https://www.bioconductor.org/). Fold changes (FCs) were calculated as the ratio of the average expression values of each probe across the samples under normal and BPH conditions. Genes with $\log \mathrm{FC} \geq 1.0$ were considered as upregulated and those with $\log \mathrm{FC} \leq-1.0$ as downregulated $(20,21)$.

Gene and functional annotation clustering. Functional annotation clustering available in the DAVID tool (https://david.ncifcrf.gov/) was performed. Associations among the 'annotation terms' were measured based on their co-association genes in order to cluster similar, redundant and heterogeneous annotation content from the similar or different resources into annotation groups, based on the protocol by Huang et al (21) from 2009.

Protein-protein interaction study. The GeneMania database (https://genemania.org/) (22) was used to infer experimentally known physical interactions between proteins to predict pathways, protein functions and potential novel therapeutic targets.

RNA tissue specificity analysis. For the purpose of RNA tissue-specific analysis, the Human Protein Atlas (HPA) (23) was used. The HPA portal maps all the human proteins in cells, tissues and organs using integrated omics technologies. In addition, the distribution of proteins in the prostate was examined using the Tissue Atlas (one of the three major HPA projects).

Molecular docking of active components of Chinese herbs to $\mathrm{BPH}$ receptor proteins. A total of 10 Chinese herbs that have been cited as effective for treating BPH were selected (Table I). Using a systematic literature review, the phytochemicals potentially contributing to the effectiveness of these herbs were retrieved and listed in Table I.

In silico extraction of phytochemical compounds. The structures of the phytochemical compounds were obtained from various databases, such as ChEMBL (24), PubChem (25) and DrugBank (26).

Molecular docking. The structures of the relevant prostate receptor proteins and the phytochemicals selected for the study (cinnamonitride, astragaloside, cornuside, polyporenic acid C, berberine and alisol A monoacetate) were first converted into pdbqt files for docking. AutoDock Vina (27) was used with receptor proteins to perform blind flexible dockings.

Interaction analysis. The Protein-Ligand Interaction Profiler (PLIP) (28) was used to establish interactions between the docked complexes.

\section{Results and Discussion}

The differentially expression genes (DEGs) in BPH were identified using the methodology described in the 'Identification of DEGs' section. Out of a variety of existing methods for identifying DEGs from microarray gene expression data, such as the FC (29) or t-test statistics (30), calculation of the $\log (\mathrm{FC})$ was 
Table I. Phytochemical compounds occurring in Chinese medicinal herbs used to treat benign prostate hyperplasia.

\begin{tabular}{ll}
\hline Chinese herb name & \multicolumn{1}{c}{ Phytochemical compound } \\
\hline Chaun Shan Jia & $\begin{array}{l}\text { N-butyl tricosylamide, cyclo } \\
\text { (L-seryl-L-tyrosyl) }\end{array}$ \\
E Shu & Curdioneandgermacrone \\
Fu ling & Polyporenic acid C \\
Huang Bo & Berberine \\
Huang Qi & Astragalosides \\
Rou Gui & Cinnamonitride \\
Shan Zhu Yu & Cornuside \\
Shu Di Huang & Rehmania polysaccharide, Jionoside \\
Wang Bu Liu Xing & Triterpene saponins \\
Ze Xie & Alisol A monoacetate \\
\hline
\end{tabular}

chosen as one of the simplest ad-hoc methods for microarray analyses. The FC describes the change in expression of a gene between two observed samples, i.e., between normal and BPH tissues (31).

After selecting the gene expression datasets and evaluating them for differential expression analysis, a boxplot of the BPH and the normal samples was generated (Fig. 1). It was observed that the median of the two sample types (i.e., BPH vs. normal) was close to zero. However, there were significant variations in terms of their minimum, first quartile, third quartile and maximum values between BPH and normal groups, with BPH samples GSM141335 and GSM141337 showing lower values compared with those in normal samples GSM141338 and GSM141339 (Fig. 1).

The $\log F C$ statistics for the entire genome were computed. The $\log F C$ values of all the genes are presented in a scatter plot in Fig. 2. Genes with a $\log F C \geq 1.0$ were considered to be upregulated and those with $\log \mathrm{FC} \leq-1.0$ were considered to be downregulated in BPH tissues $(32,33)$. Following conventional rules, a threshold of a two-fold change in gene expression (i.e., $-1.0 \leq \log \mathrm{FC} \geq 1.0)$, and $\mathrm{P} \leq 0.05(5 \%$ significance level) were used to short-list DEGs in BPH. Table II lists the identified DEGs with their P-values and $\log \mathrm{FC}$ values. Among the highest ranking identified DEGs are Zinc finger proteins $(\mathrm{ZNF} 3 ; \mathrm{P}<0.0001, \log \mathrm{FC}=3.0111)$, Acyl-CoA synthetase family member 3 (ACSF3; $\mathrm{P}<0.0001$, $\log \mathrm{FC}=1.5768)$, Fibrinogen like-1 (FGL1; $\mathrm{P}=0.0001$, $\log \mathrm{FC}=-1.4845)$, PMS1 homolog 1 , mismatch repair system component $(\mathrm{PMS} 1 ; \mathrm{P}=0.0001, \log \mathrm{FC}=-1.4611)$, Forkhead box P2 (FOXP2; $\mathrm{P}<0.0001, \log \mathrm{FC}=-1.3491)$, anterior gradient 2 (AGR2; $\mathrm{P}<0.0001, \log \mathrm{FC}=-1.3156)$ andRing finger protein 135 ( $\mathrm{RNF} 135 ; \mathrm{P}=0.0001, \log \mathrm{FC}=1.2748$ ). In addition, profile graphs of identified DEGs were plotted to obtain a graph of DEG expression across the different samples, as presented in Fig. 3. The profile graphs point to differential expression behaviours in the BPH and normal prostate samples.

The list of identified DEGs was validated against the published literature in order to find evidence for their involvement in BPH or other prostatic conditions. It was revealed that, for instance, the association of the genes

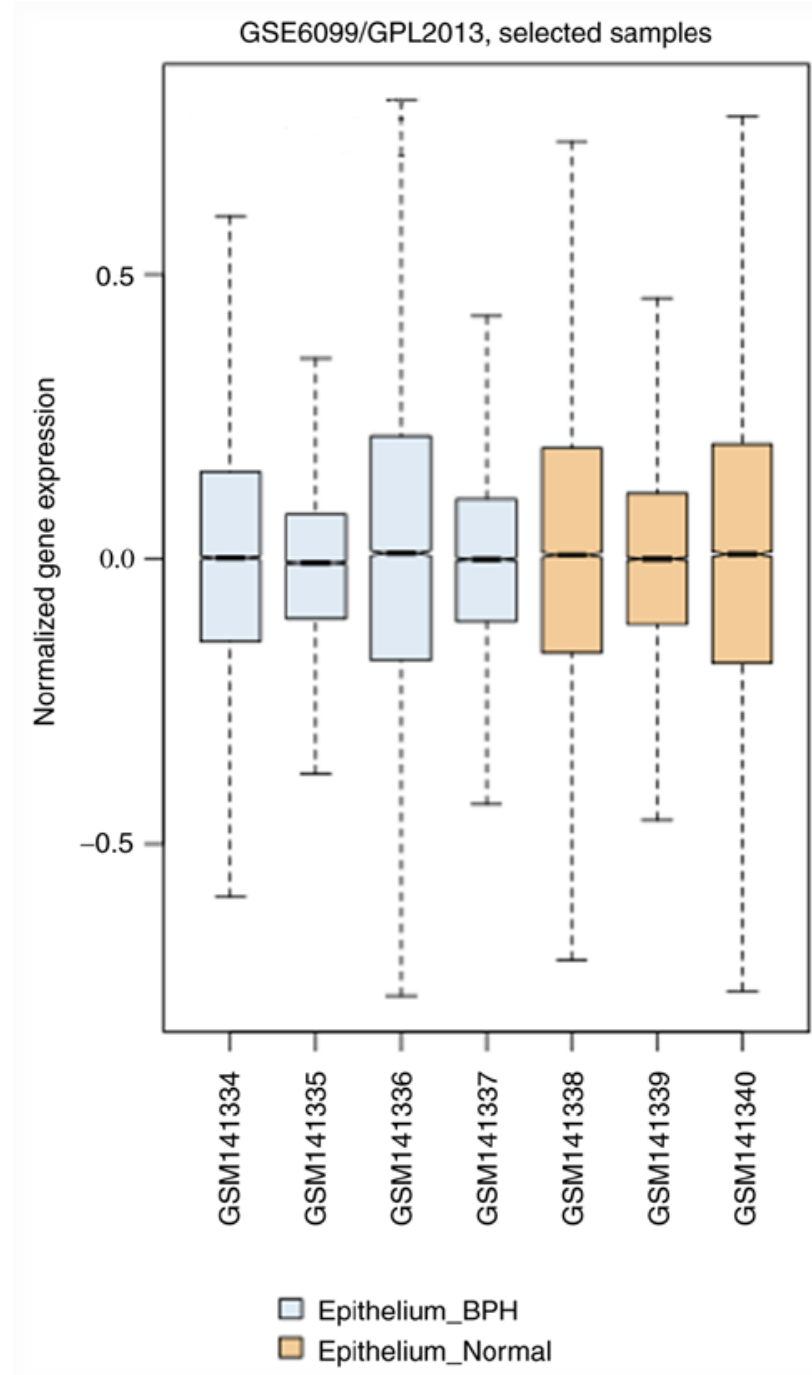

Figure 1. Boxplot of gene expression between BPH samples and normal samples. The $\mathrm{x}$-axis represents samples, whilst the $\mathrm{y}$-axis represents the normalized gene expression of a sample. All the samples show fairly consistent medians across all the samples, however, a smaller interquartile range is observed in BPH samples (GSM141335 and GSM141337) compared to all the three normal samples. BPH, benign prostate hyperplasia.

ADAM metallopeptidase with thrombospondin type 1 motif 1 (ADAMTS1) (34), folate hydrolase 1 (FOLH1) or Prostate-specific membrane antigen (35) and insulin like growth factor binding protein 5 (IGFBP5) (36) with BPH was listed in the DisGeNET database (37). Modified ADAMTS1 expression results in markedly changed blood vessel morphology and altered thrombospondin-1(TSP1) levels in tumors. Loss of ADAMTS1 is associated with small-diameter vessels that are consistent with more aggressive prostate tumors (38). These results suggest that ADAMTS1 is an important regulatory factor of tumor growth and angiogenesis during prostate cancer progression. According to the Human Protein Atlas (https://www.proteinatlas.org/), ADAMTS1RNA expression is significantly enhanced in prostate tissue. The DisGeNET database reports that PMS1 is a biomarker of malignant prostate neoplasms $(39,40)$, and anterior gradient 2(AGR2) is highly associated with prostate neoplasms (41-44) and prostate carcinoma (44). Zinc finger proteins (ZNF) ZNF91 (45), ZFX (46), ZNF185 (47), ZNF132 (48) and myc 


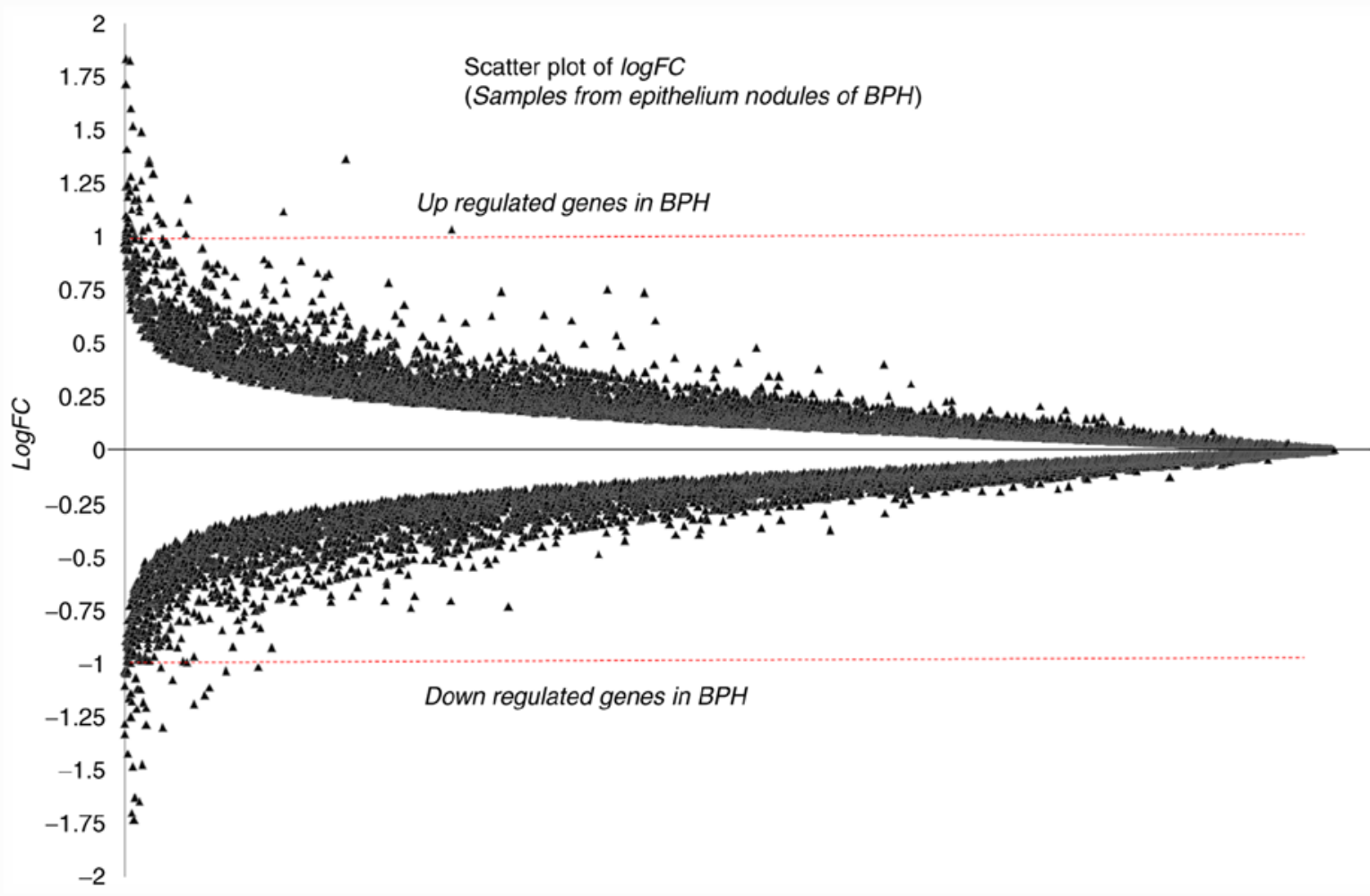

Figure 2. Scatter plot showing the $\log \mathrm{FC}$ of differentially expression genes in BPH. The $\mathrm{x}$-axis represents genes whereas the y-axis represents the logFC values. $\mathrm{BPH}$, benign prostate hyperplasia; $\mathrm{FC}$, fold change.

associated zinc finger protein (49), as the family of ZNF3, have been associated with prostate pathology, prostate cancer progression and prostate cancer pathogenesis. The association of zinc finger proteins with $\mathrm{BPH}$ and prostate cancer was reviewed in Rahman (50) in 2016. Fibrinogen like-1 (FGL1) has been associated with prostate cancer and high-grade prostatic intraepithelial neoplasia (HGPIN) (51). Collagen type XII $\alpha 1$ chain (COL12A1) is upregulated in BPH (52-54). Similarly, other identified DEGs are involved in different prostate diseases. One of the key biomarkers involved in BPH, but not in prostate cancer, is Steroid $5 \alpha$-reductase 2 (SRD5A 2) (55-58). It was not identified in the differential expression analysis of the present study, but it was considered for drug interaction studies.

Another gene identified in this analysis was FOLH1, also known as prostate-specific membrane antigen. It encodes a type II transmembrane glycoprotein expressed in a number of tissues, including the prostate. In the prostate, FOLH1 is upregulated in cancerous cells, has been used as a diagnostic and prognostic marker for prostate cancer (59) and was also proposed as a possible marker for neurological disorders such as Alzheimer's and Huntington's disease (60). According to GeneCards, the Human Gene Database (https://www.genecards.org), FOLH1 is involved in prostate tumor progression $(61,62)$. Finally, insulin-like growth factor binding proteins (IGFBPs) exhibit abnormalities in prostatic stromal cells in BPH $(36,63)$.

Gene and functional annotation clustering. Clustered annotations make the functional analyses more clear and focused. Clustering algorithms rely on the hypothesis that similar annotations should have similar gene members (64). The functional annotation clustering of the present study used Kappa statistics to estimate the degree of the common genes between two annotations, and fuzzy heuristic clustering was used to classify the groups of similar annotations based on kappa values. Hence, common gene annotations have a high chance of being grouped together. This eases the biological analysis and interpretation at the group level.

After gene clustering and functional annotation clustering, only two gene clusters were obtained with the 'lowest' classification stringency. The first cluster contained five genes, namely bromo domain adjacent to zinc finger domain $2 \mathrm{~B}$, TEA domain transcription factor 1 (TEAD1), erythroid differentiation regulatory factor 1, ZNF3 and forkhead box P2with an enrichment score of 0.68 and the second cluster contained only three genes, namely $\beta$-secretase 2, ADAMTS1 and FOLH1 with an enrichment score of 0.47 . Fig. 4 presents a 2D view of clustered genes with their associated gene terms.

For the functional annotation clustering analysis, a 'high' classification stringency was selected and 4 annotation clusters were obtained, as presented in Table III and Fig. 5. Out of the 4 clusters (Table III and Fig. 5), the first 3 were significantly enriched (enrichment scores of $0.95,0.70$ and 0.52 ). The P-values of functional Gene Ontology terms of these 3 significantly enriched clusters are also reasonably acceptable. Each of the four terms within cluster 1 was associated with both overlapping as well as differing genes (Fig. 5B). The terms of clusters 2 and 4 were only associated with overlapping genes.

Protein interaction analysis. Protein-protein interactions (PPIs) have a crucial role in cells and control essential 


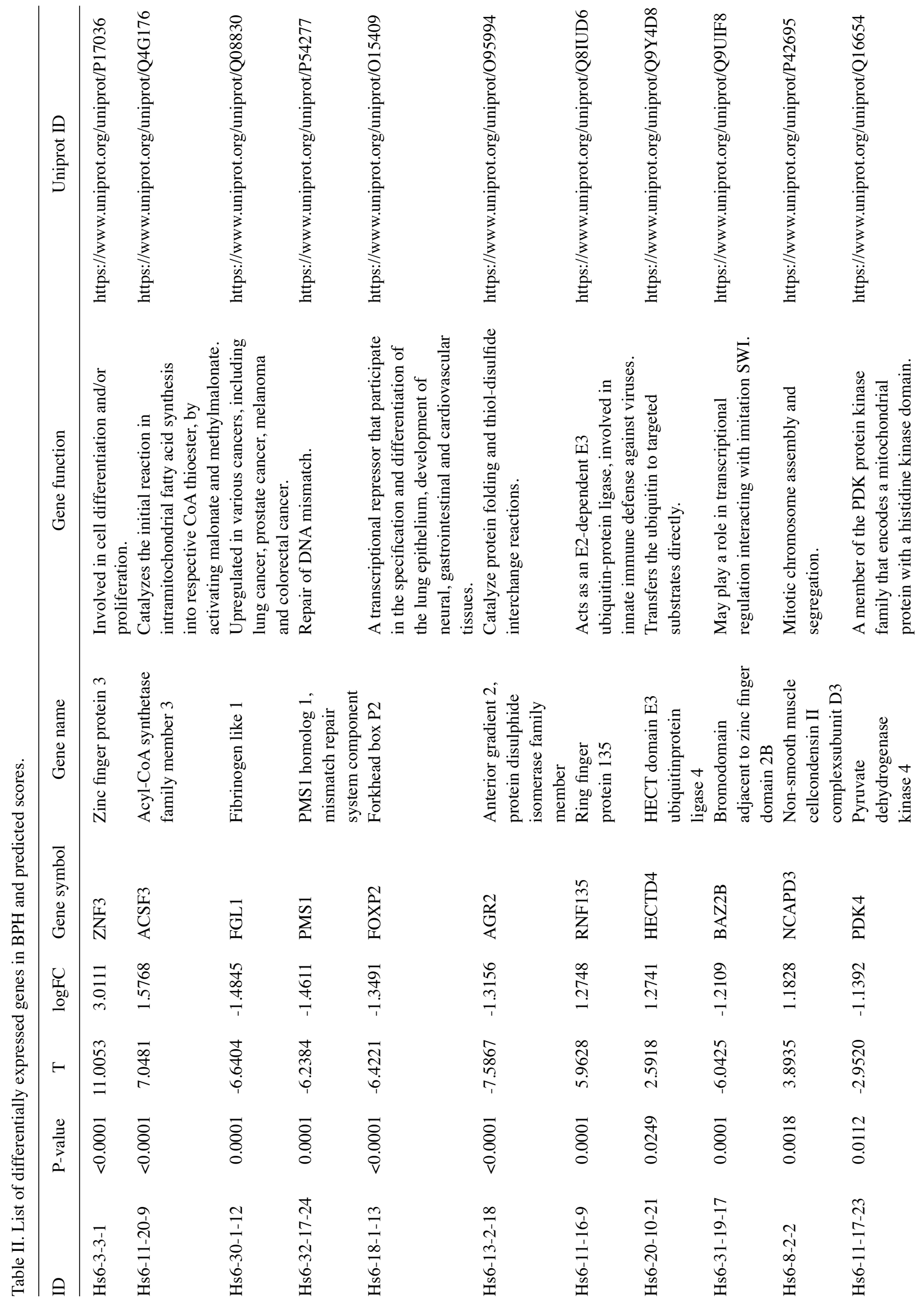




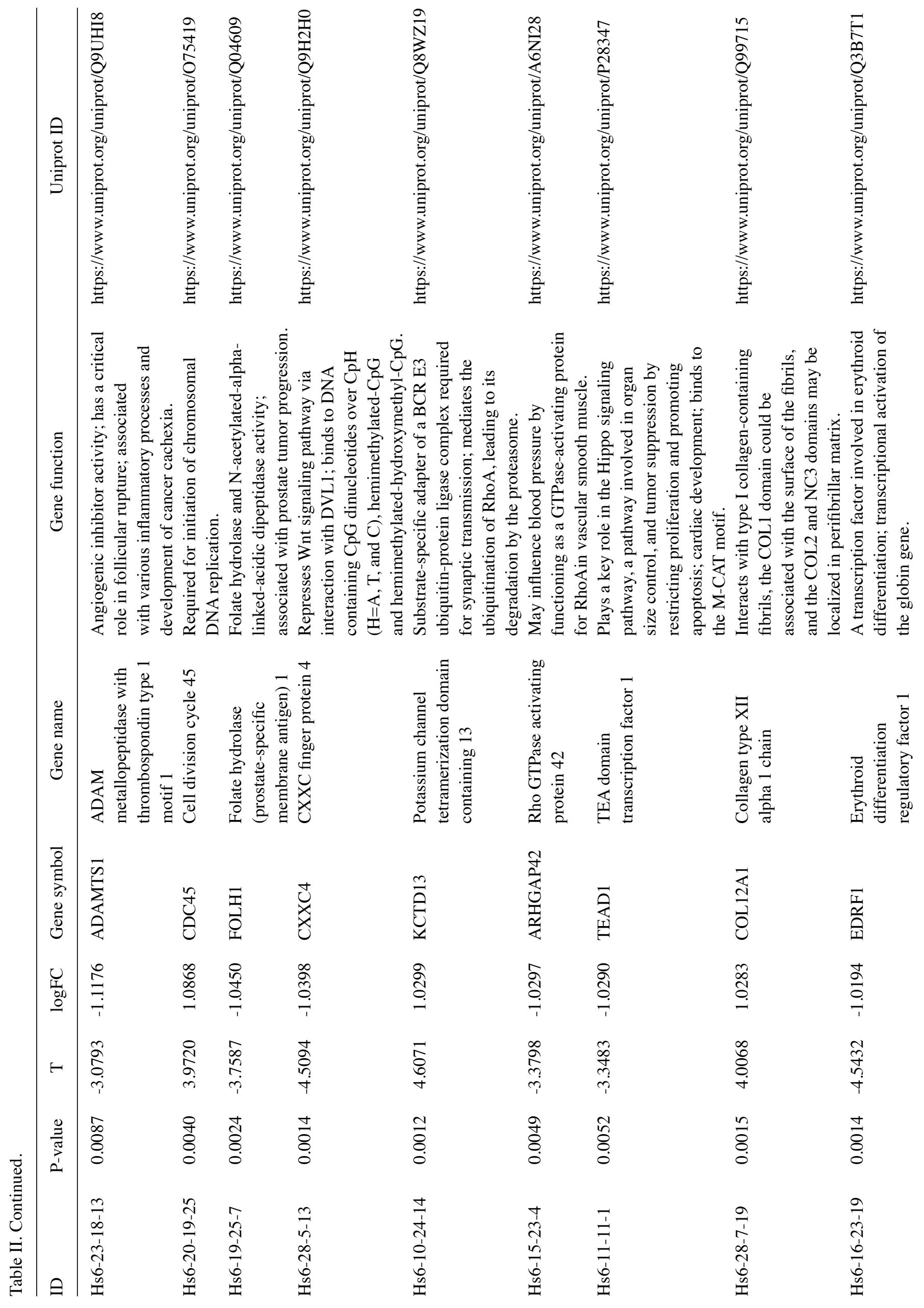




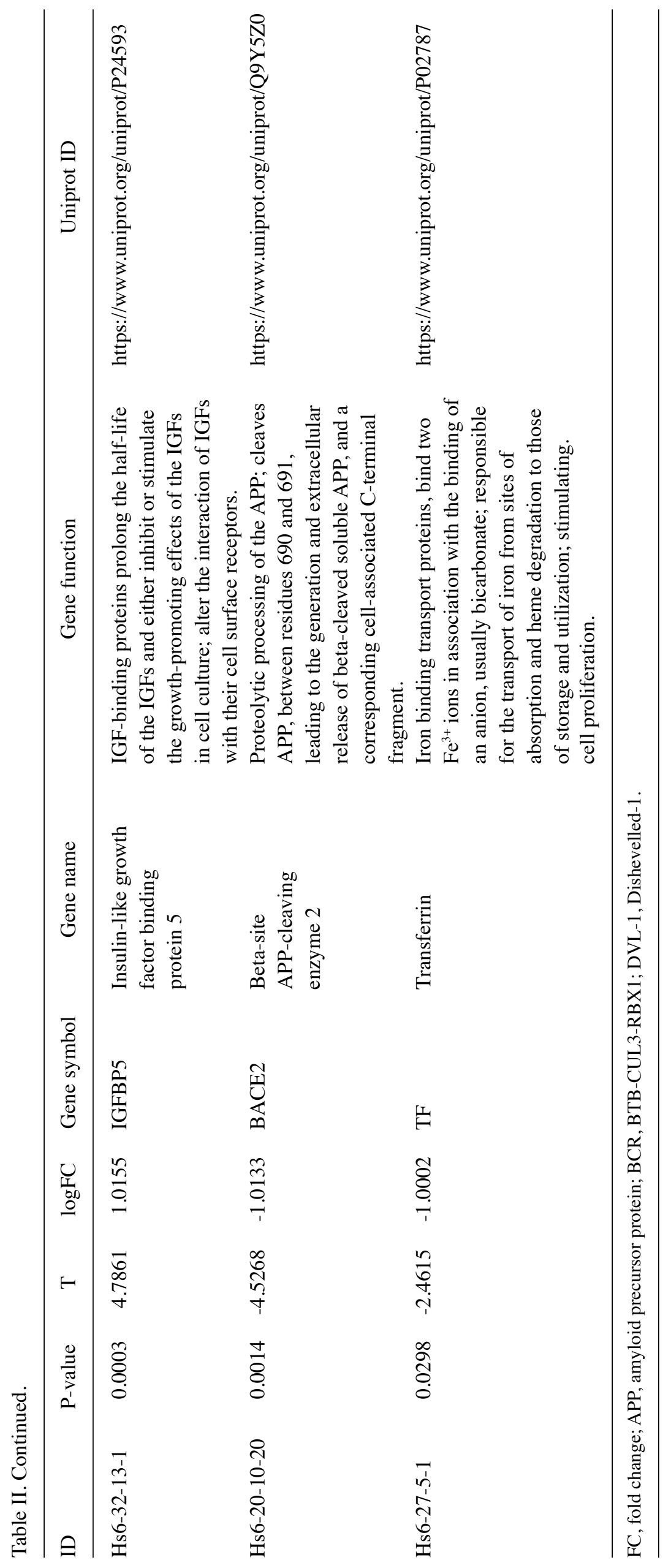




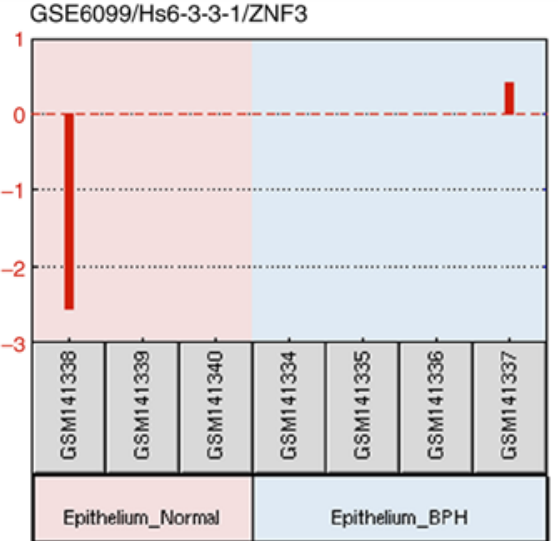

- Expression value

GSE6099/Hs6-18-1-13/FOXP2

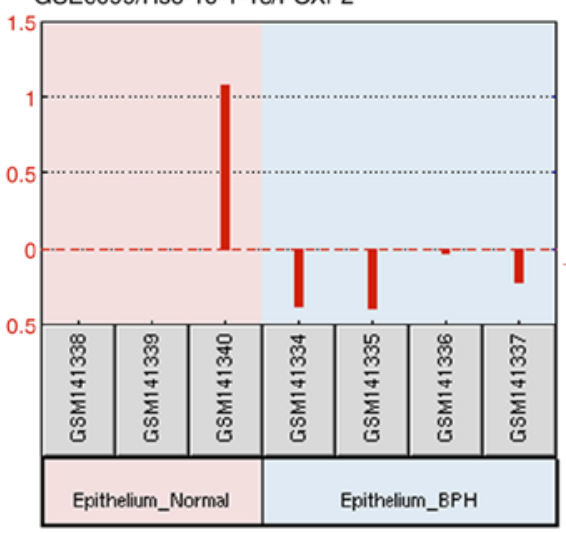

- Expression value

GSE6099/Hs6-31-19-17/BAZ2B

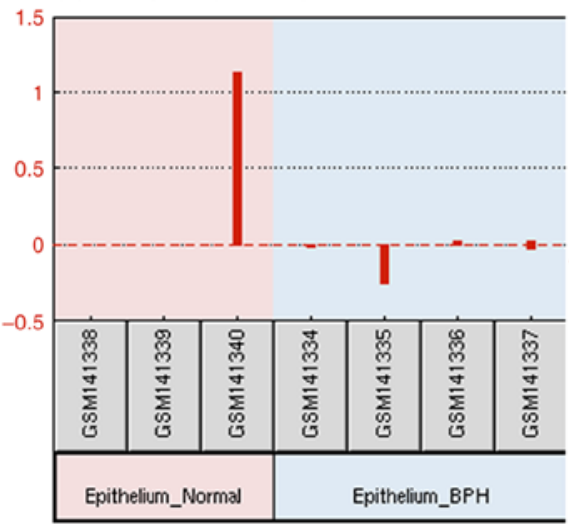

- Expression value

GSE6099/GPL2013/CDC45

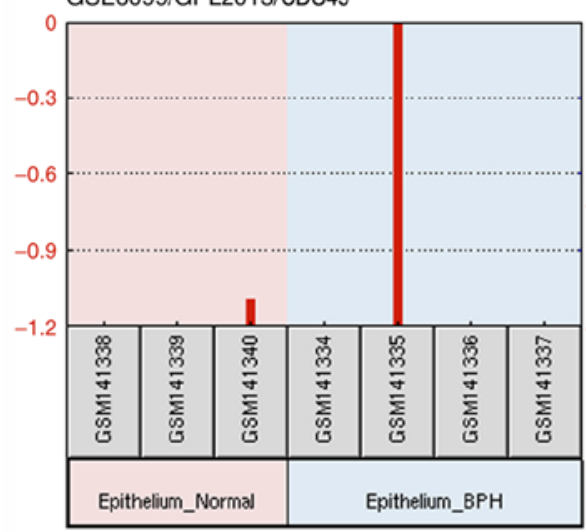

- Expression value
GSE6099/Hs6-11-20-9/ACSF3

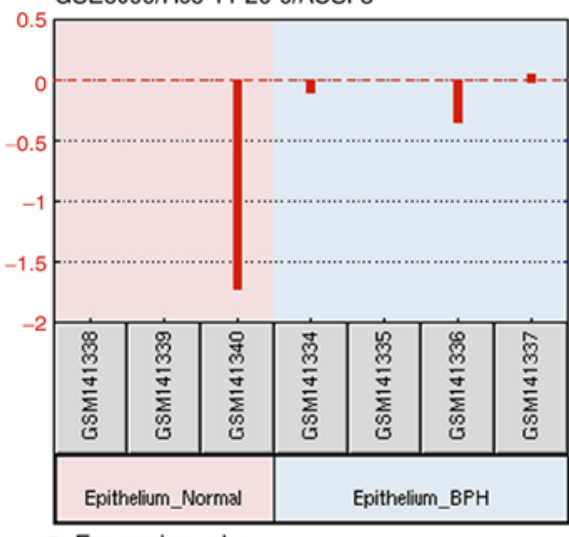

- Expression value

GSE6099/Hs6-13-2-18/AGR2

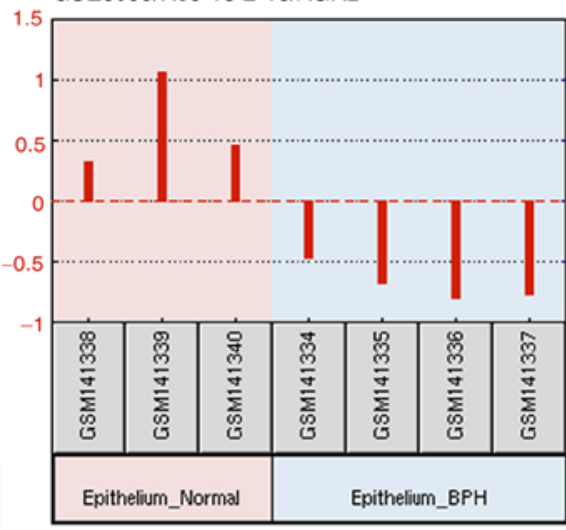

- Expression value

GSE6099/Hs6-8-2-2/NCAPD3

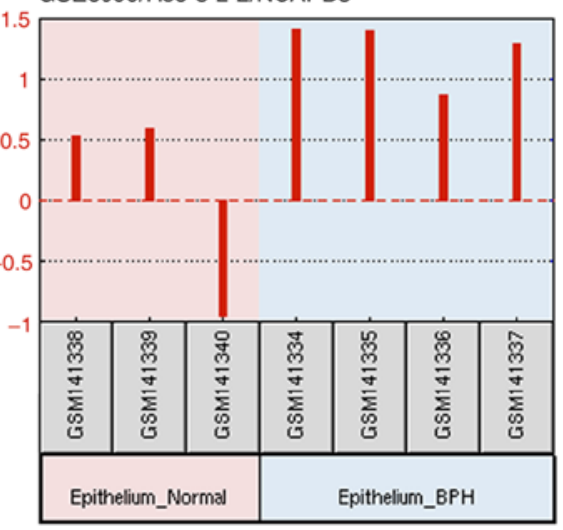

- Expression value

GSE6099/GPL2013/FOLH1

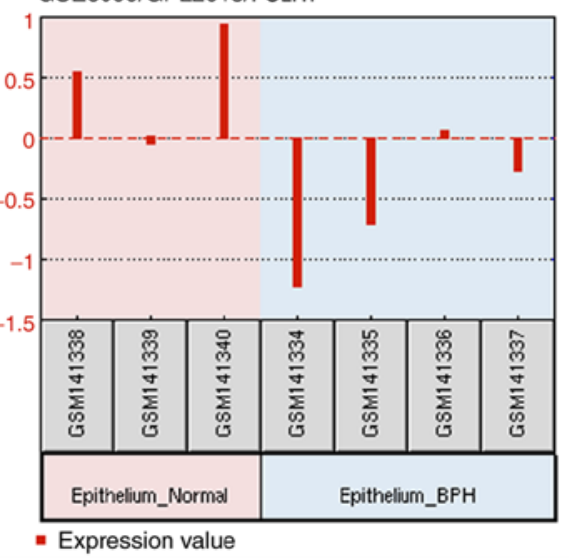

GSE6099/Hs6-30-1-12/FGL1

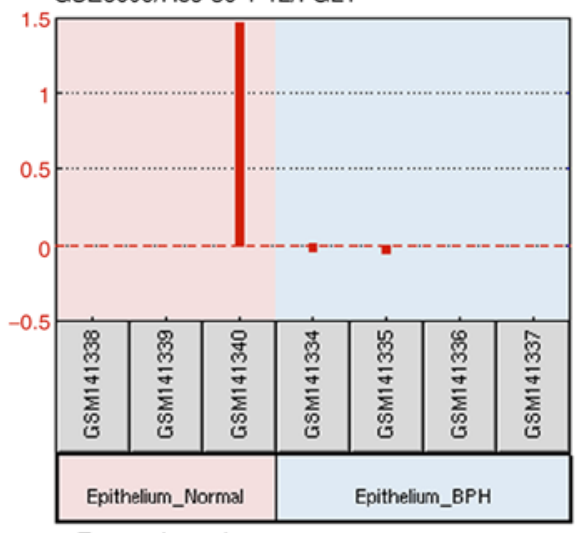

- Expression value

GSE6099/Hs6-11-16-9/RNF135

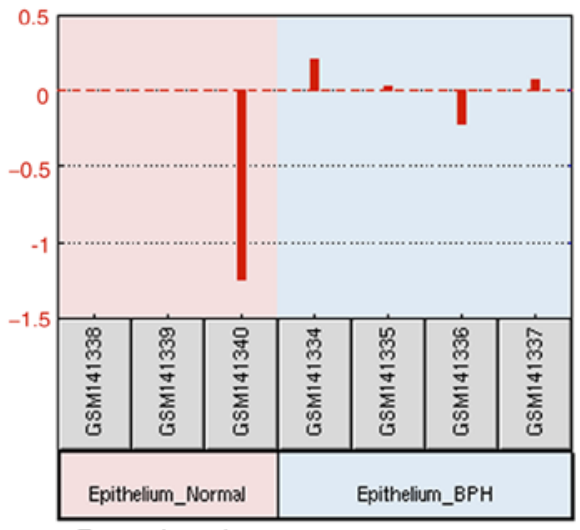

- Expression value

GSE6099/GPL2013/PDK4

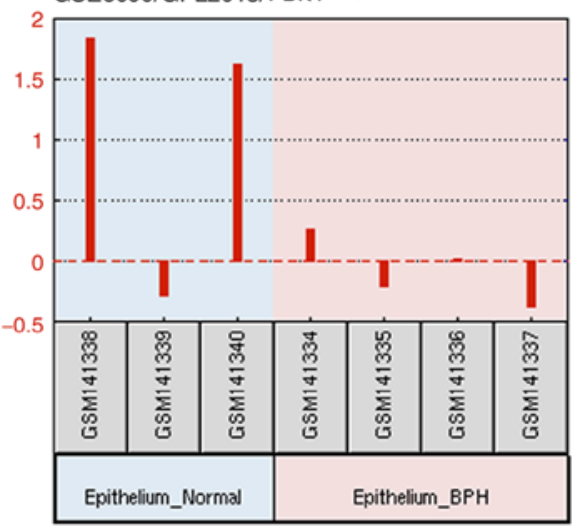

- Expression value

GSE6099/GPL2013/CXXC4

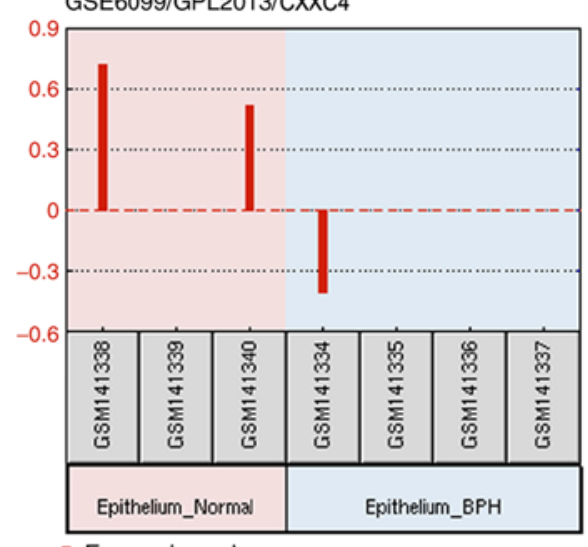

- Expression value 


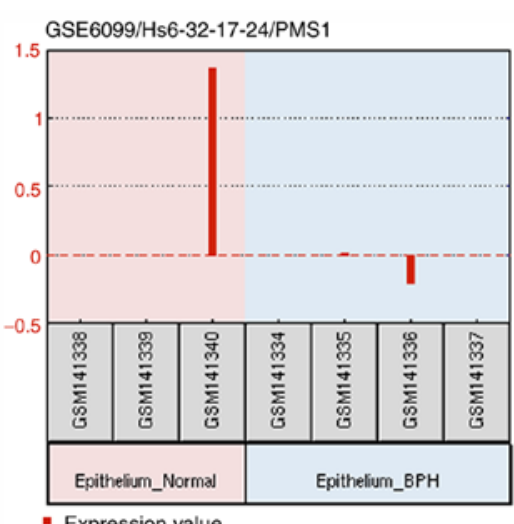

Expression value

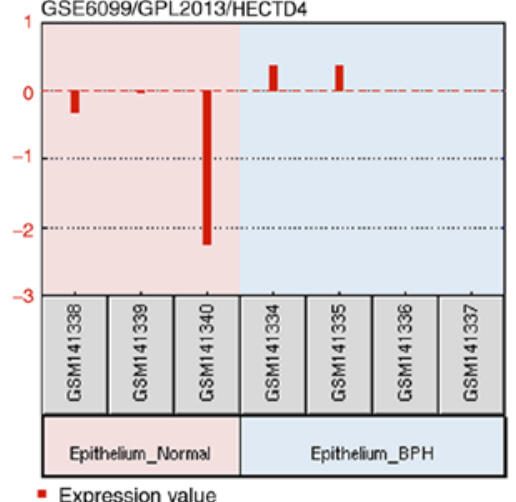

GSE6099/GPL2013/ADAMTS1

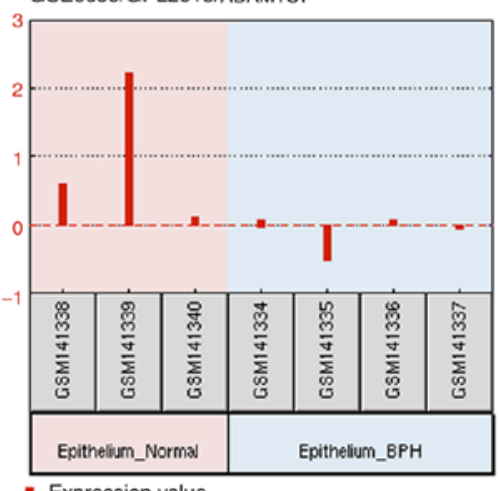

- Expression value

GSE6099/GPL2013/KCTD13

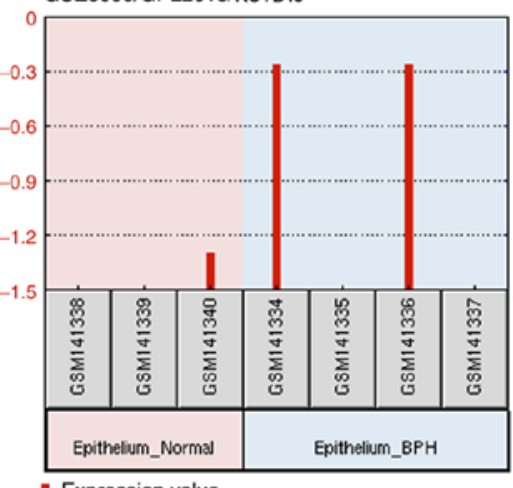

GSE6099/GPL2013/ARHGAP42

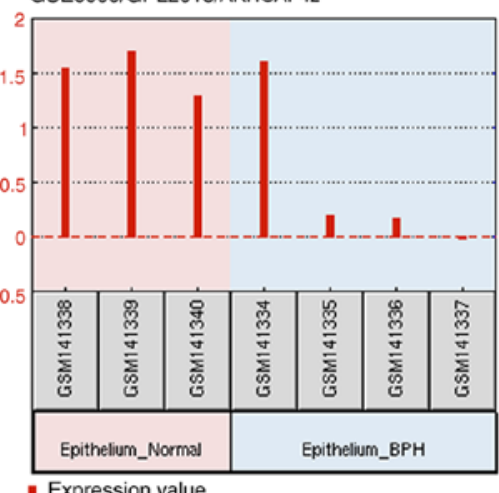

GSE6099/GPL2013/IGFBP5

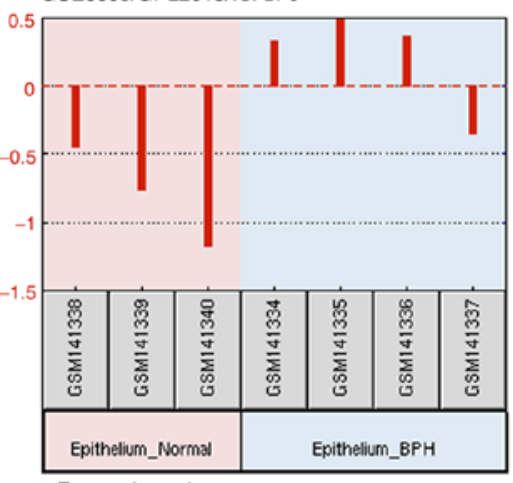

- Expression value

GSE6099/GPL2013/TEAD1

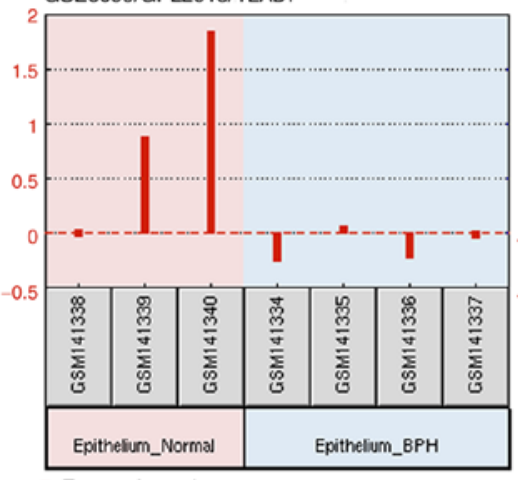

- Expression value

GSE6099/GPL2013/BACE2

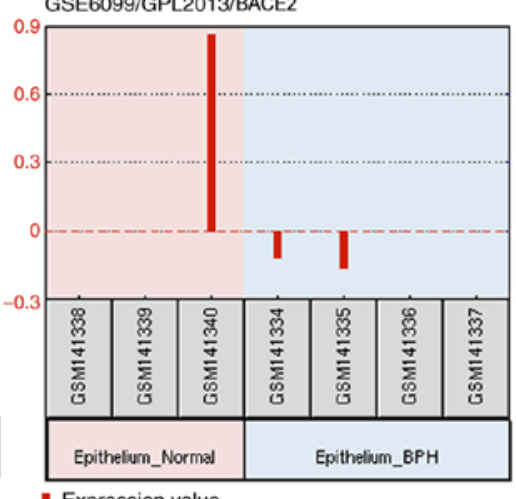

- Expression value
GSE6099/GPL2013/COL12A1

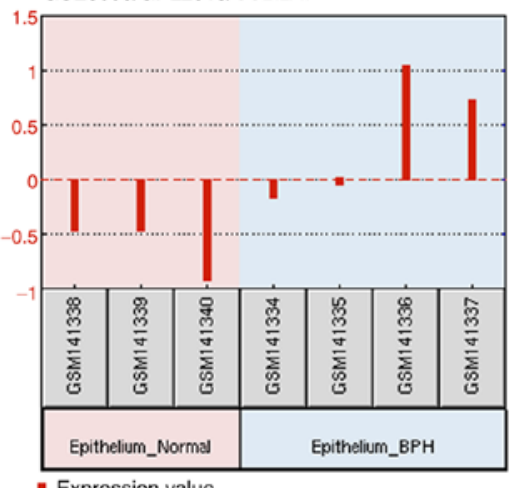

pression value

GSE6099/GPL2013/TF

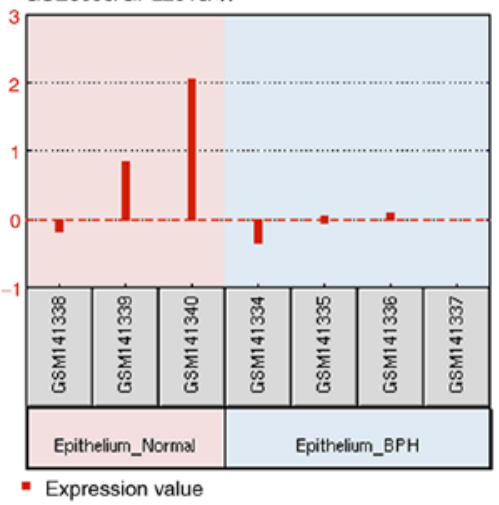

GSE6099/GPL2013/EDRF1

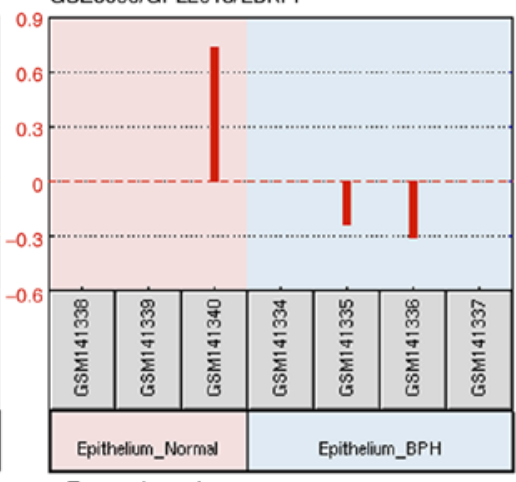

- Expression value

Figure 3. Profile graphs of differentially expressed genes, namely ZNF3, ACSF3, FGL1, FOXP2, AGR2, RNF135, BAZ2B, NCAPD3, PDK4, CDC45, FOLH1, CXXC4, PMS1, ARHGAP42, COL12A1, HECTD4, IGFBP5, TF, ADAMTS1, TEAD1, EDRF1, KCTD13 and BACE2. BPH, benign prostate hyperplasia; ZNF3, Zinc finger protein 3; ACSF3, Acyl-CoA synthetase family member 3; FGL1, Fibrinogen like 1; FOXP2, Forkhead box P2; AGR2, Anterior gradient 2; RNF135, Ring finger protein 135; BAZ2B, Bromodomain adjacent to zinc finger domain 2B; NCAPD3, Non-smooth muscle cell condensin II complex subunit D3; PDK4, Pyruvate dehydrogenase kinase 4; CDC45, Cell division cycle 45; FOLH1, Folate hydrolase (prostate-specific membrane antigen) 1; CXXC4, CXXC finger protein 4; PMS1, PMS1 homolog 1, mismatch repair system component; ARHGAP42, Rho GTPase activating protein 42; COL12A1, collagen type XII a1 chain; HECTD4, HECT domain E3 ubiquitin protein ligase 4; IGFBP5, Insulin-like growth factor binding protein 5; TF, Transferrin; ADAMTS1, ADAM metallopeptidase with thrombospondin type 1 motif 1; TEAD1, TEA domain transcription factor 1; EDRF1, Erythroid differentiation regulatory factor 1; KCTD13, Potassium channel tetramerization domain containing 13; BACE2, Beta-site APP-cleaving enzyme 2. 
A

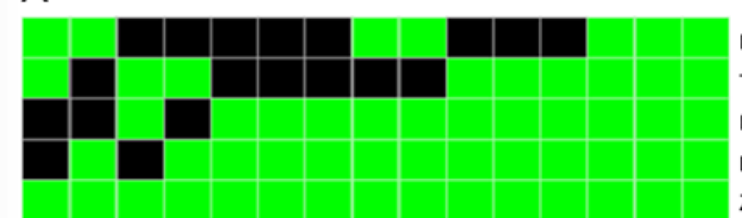

Erythroid differentiation regulatory factor 1 (EDRF1)

TEA domain transcription factor 1 (TEAD1)

Forkhead box P2 (FOXP2)

Bromodomain adjacent to zinc finger domain 2B (BAZ2B)

Zinc finger protein 3 (ZNF3)

B
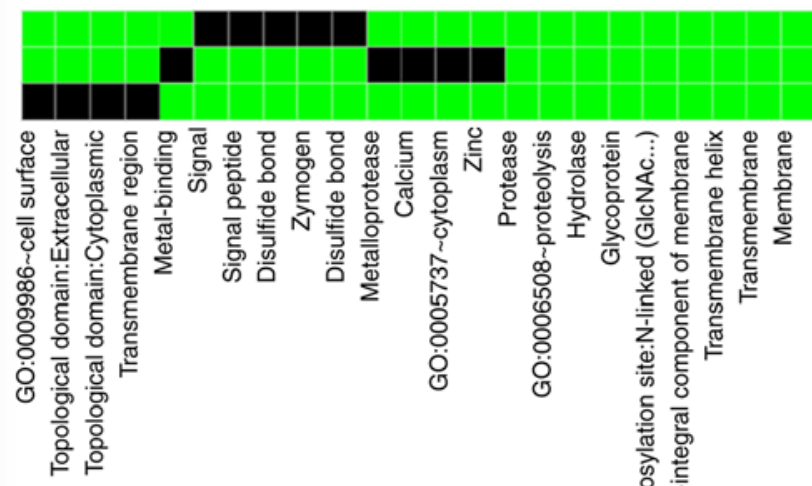

Folate hydrolase 1 (FOLH1)

$\beta$-site APP-cleaving enzyme 2 (BACE2)

ADAM metallopeptidase with thrombospondin type 1 motif 1 (ADAMTS1)

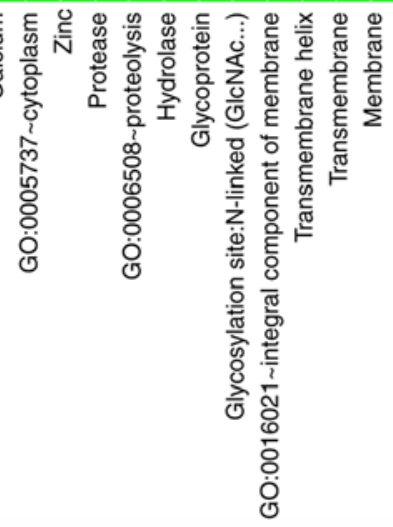

Figure 4. Two-dimensional view of clustered genes with their associated GO gene-terms. (A) Gene cluster 1; (B) gene cluster 2. GO, gene ontology.

cellular and biological processes. Any disease-causing mutations affecting PPIs may lead to disruption of protein-DNA interactions, protein misfolding and new undesirable interactions (65). A better understanding of possible PPIs allows for the prediction of pathways, protein functions and potential novel therapeutic targets. In the present study, gene interactions were predicted using the GeneMania tool with customized gene-gene interaction parameters, such as physical interactions and gene co-expression interactions only, as presented in Fig. 6. The physical interactions are depicted in pink, while co-expression interactions are displayed in purple. The maximum resultant genes and maximum resultant attributes were set to default, i.e., 20 and 10, respectively. The genes that do not interact with any other genes under these parameter settings were removed from the network (Fig. 6). This way, 3 different interaction networks were obtained (Fig. 6). The size of the nodes represents the gene score, i.e., the degree with which GeneMania predicted the gene-gene association. Similarly, the thickness of the edges represents the strength of the interaction. The topological analysis of gene-gene interactions suggested that the genes IGFBP5, TEAD1 and transferrin are hub genes that have direct or indirect interactions with other DEGs identified. Most of these interactions are physical interactions with good strengths (pink color). This suggests that these DEGs may be used for the rapeutic strategies and as drug targets $(66,67)$. 
Table III. Results of functional annotation clustering analysis.

A, Annotation cluster 1 (enrichment score: 0.95)

\begin{tabular}{|c|c|c|c|c|c|c|}
\hline Category & Term & Count & P-value & Genes & Benjamini & FDR \\
\hline UP_KEYWORDS & Secreted & 6 & 0.0526 & $\begin{array}{l}\text { TF, COL12A1, ADAMTS1, } \\
\text { FGL1, AGR2, IGFBP5 }\end{array}$ & 0.9020 & 44.1446 \\
\hline UP_KEYWORDS & Signal & 8 & 0.1386 & $\begin{array}{l}\text { TF, CDC45, BACE2, } \\
\text { COL12A1, ADAMTS1, } \\
\text { FGL1, AGR2, IGFBP5 }\end{array}$ & 0.8822 & 79.9935 \\
\hline UP_SEQ_FEATURE & Signal peptide & 7 & 0.1472 & $\begin{array}{l}\text { TF, BACE2, COL12A1, } \\
\text { ADAMTS1, FGL1, AGR2, } \\
\text { IGFBP5 }\end{array}$ & 1.0000 & 85.0691 \\
\hline UP_KEYWORDS & Disulfide bond & 7 & 0.1475 & $\begin{array}{l}\text { TF, BACE2, COL12A1, } \\
\text { ADAMTS1, FGL1, AGR2, } \\
\text { IGFBP5 }\end{array}$ & 0.8592 & 82.1005 \\
\hline
\end{tabular}

B, Annotation cluster 2 (enrichment score: 0.70 )

\begin{tabular}{|c|c|c|c|c|c|c|}
\hline Category & Term & Count & P-value & Genes & Benjamini & FDR \\
\hline UP_KEYWORDS & Protease & 3 & 0.1139 & FOLH1, BACE2, ADAMTS1 & 0.9257 & 72.8568 \\
\hline GOTERM_BP_DIRECT & $\begin{array}{l}\text { GO:0006508 } \\
\text { proteolysis }\end{array}$ & 3 & 0.1283 & FOLH1, BACE2, ADAMTS1 & 0.9987 & 80.3993 \\
\hline UP_KEYWORDS & Hydrolase & 3 & 0.5431 & FOLH1, BACE2, ADAMTS1 & 0.9810 & 99.9785 \\
\hline
\end{tabular}

C, Annotation cluster 3 (enrichment score: 0.52)

\begin{tabular}{|c|c|c|c|c|c|c|}
\hline Category & Term & Count & P-value & Genes & Benjamini & FDR \\
\hline UP_KEYWORDS & $\begin{array}{l}\text { Transcription } \\
\text { regulation }\end{array}$ & 5 & 0.2338 & $\begin{array}{l}\text { EDRF1, TEAD1, BAZ2B, } \\
\text { ZNF3, FOXP2 }\end{array}$ & 0.8282 & 94.3394 \\
\hline UP_KEYWORDS & Transcription & 5 & 0.2496 & $\begin{array}{l}\text { EDRF1, TEAD1, BAZ2B, } \\
\text { ZNF3, FOXP2 }\end{array}$ & 0.8287 & 95.4801 \\
\hline GOTERM_BP_DIRECT & $\begin{array}{l}\text { GO:0006351 } \\
\text { transcription, } \\
\text { DNA-templated }\end{array}$ & 4 & 0.4491 & $\begin{array}{l}\text { EDRF1, BAZ2B, ZNF3, } \\
\text { FOXP2 }\end{array}$ & 1.0000 & 99.9156 \\
\hline
\end{tabular}

D, Annotation cluster 4 (enrichment score: 0.01 )

\begin{tabular}{|c|c|c|c|c|c|c|}
\hline Category & Term & Count & P-value & Genes & Benjamini & FDR \\
\hline GOTERM_CC_DIRECT & $\begin{array}{l}\text { GO:0016021 } \\
\text { integral component } \\
\text { of membrane }\end{array}$ & 4 & 0.9615 & $\begin{array}{l}\text { FOLH1, BACE } 2, \text { HECTD4, } \\
\text { ADAMTS1 }\end{array}$ & 1.0000 & 100 \\
\hline UP_KEYWORDS & $\begin{array}{l}\text { Transmembrane } \\
\text { helix }\end{array}$ & 4 & 0.9631 & $\begin{array}{l}\text { FOLH1, BACE2, HECTD4, } \\
\text { ADAMTS1 }\end{array}$ & 1.0000 & 100 \\
\hline UP_KEYWORDS & Transmembrane & 4 & 0.9637 & $\begin{array}{l}\text { FOLH1, BACE2, HECTD4, } \\
\text { ADAMTS1 }\end{array}$ & 1.0000 & 100 \\
\hline UP_KEYWORDS & Membrane & 4 & 0.9958 & $\begin{array}{l}\text { FOLH1, BACE2, HECTD4, } \\
\text { ADAMTS1 }\end{array}$ & 1.0000 & 100 \\
\hline
\end{tabular}

FDR, false discovery rate; GO, gene ontology; BP, biological process; CC, cellular component.

RNA tissue specificity analysis. Genes have unique expression patterns that are broadly classified as tissue-specific or housekeeping. In a multicellular organism, knowledge of the tissue-specificity of a gene contributes to a better 

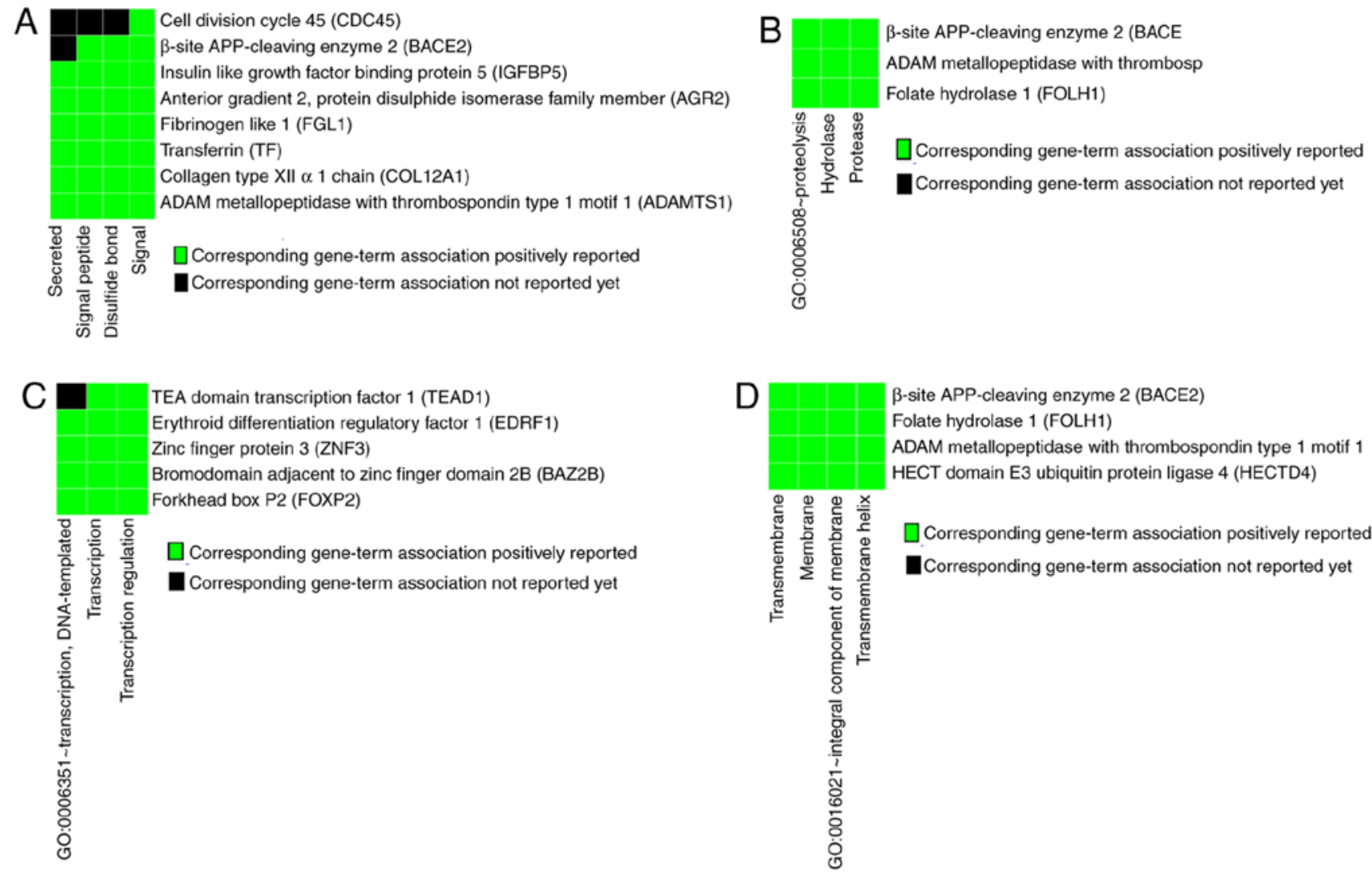

Figure 5. Functional annotation clustering analysis performed using the DAVID tool. (A) Annotation cluster 1; (B) annotation cluster 2; (C) annotation cluster 3; (D) annotation cluster 4. GO, gene ontology.

understanding of its function (68). In the present study, tissue specificity was measured by counting the number of tissues each gene was expressed in.

Both disease and trait phenotypes are under dynamic tissue-specific regulation. The major purpose of performing RNA tissue specificity analyses was to better understand how the expression of genes and its regulatory processes may be affected by disease or other biological factors. The ADAMTS1 gene is expressed in numerous tissues, including the ovary, adipose tissue, gallbladder and placenta. Fig. 7 presents the results of the tissue specificity analysis of certain DEGs in BPH identified in the present study. It was observed that the prostate tissue specificity score of all of the DEGs identified was low (normalized expression, $<25$ ), and the differential expression of these genes in BPH samples may be due to genetic variations leading to $\mathrm{BPH}$.

\section{Molecular docking and interaction analysis}

Extraction of phytochemical compounds. In the present study, only six compounds (namely cinnamonitride, astragaloside, cornuside, polyporenic acid $\mathrm{C}$, berberine and alisol $\mathrm{A}$ monoacetate) were considered, since they have been used for the treatment of BPH and its phytochemical compound structures are available.

Docking. By docking ligands (phytochemical compounds) to receptor proteins, it was indicated that polyporenic acid $\mathrm{C}$ and alisol A were notable to bind to the proteins under any of the tested conditions. Dockings were possible only between the prostatic receptors and cinnamonitride, astragaloside, berberine and cornuside. Fig. 8 presents the best binding positions for each receptor-ligand complex docking.

Interaction analysis. After comparing the dockings, it was revealed that berberine had the higher binding affinity for BPH target receptors. Therefore, the best-bound complexes with berberine were selected and subjected to a PLIP interaction analysis. Fig. 9 demonstrates interactions formed between berberine and the selected target receptors, including hydrophobic interactions, hydrogen bonds and salt bridges. Out of the four complexes subjected to the interaction analysis, the interactions formed between AGR2 (protein databank ID, 2LNT) and berberine were the most stable due to a balance between the number of hydrogen and hydrophobic bonds. The complex between berberine and AGR2 had 5 hydrogen bonds stabilizing the complex (the more hydrogen bonds in a complex, the more stable the complex).

Conclusions. In the present study, genes with differential expression between BPH and normal prostatic tissues were discovered and interaction analyses associated with BPH phenotypes were performed. A general framework for mapping complex interactions from genome-wide genotype data was established and interactions with Chinese herbal drugs were identified.

The recent discovery of novel genomic mutations and the availability of high-throughput screening and microarray technologies have facilitated the uncovering of gene 


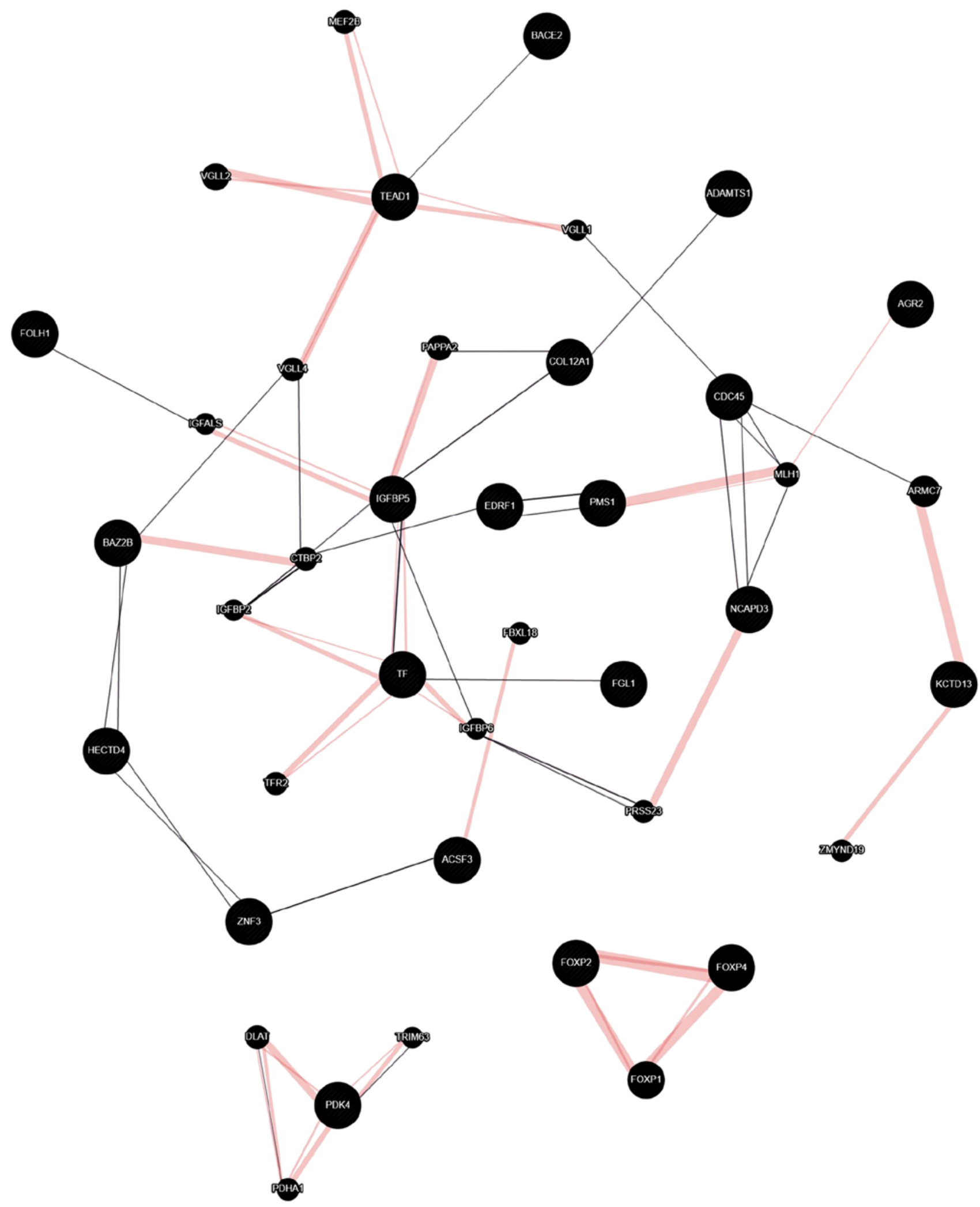

Figure 6. Map of interactions among genes. Gene-gene physical interactions (pink edges) and gene co-expression interactions only (black edges). The larger size nodes in the interaction network represent the differentially expressed genes identified in this study, whilst smaller nodes represent other interacting genes.

biomarkers for the diagnosis, prognosis and treatment of various diseases, such as BPH (31-33). With the help of in silico approaches, high-throughput microarray data were analyzed to identify DEGs as biomarkers for BPH; furthermore, PPI, gene clustering and tissue specificity analyses were performed to associate their expression to BPH phenotypes. In addition, molecular docking studies of certain short-listed gene biomarkers [AGR2 (2LNT), SRD5A2 (6OQX), ZNF3 (5T00) and COL12A1 (1U5M)] were performed to identify alternative Chinese herbal drugs for the treatment of BPH. The 


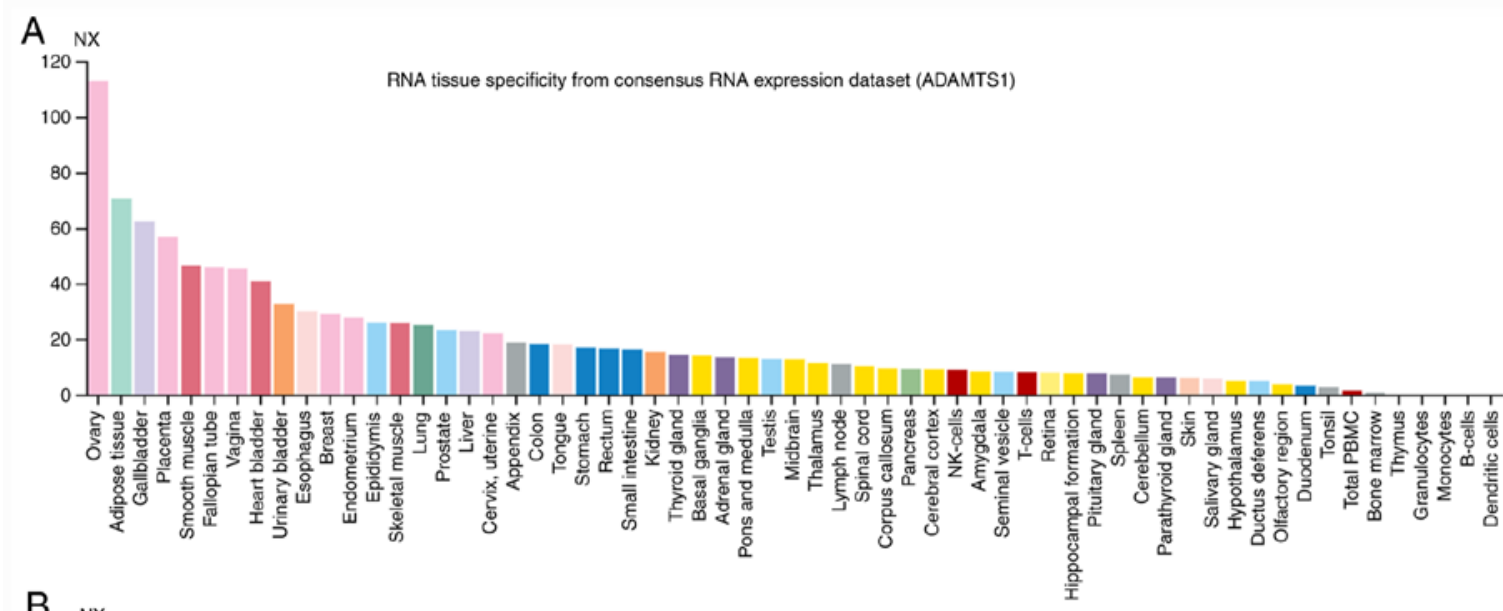

B
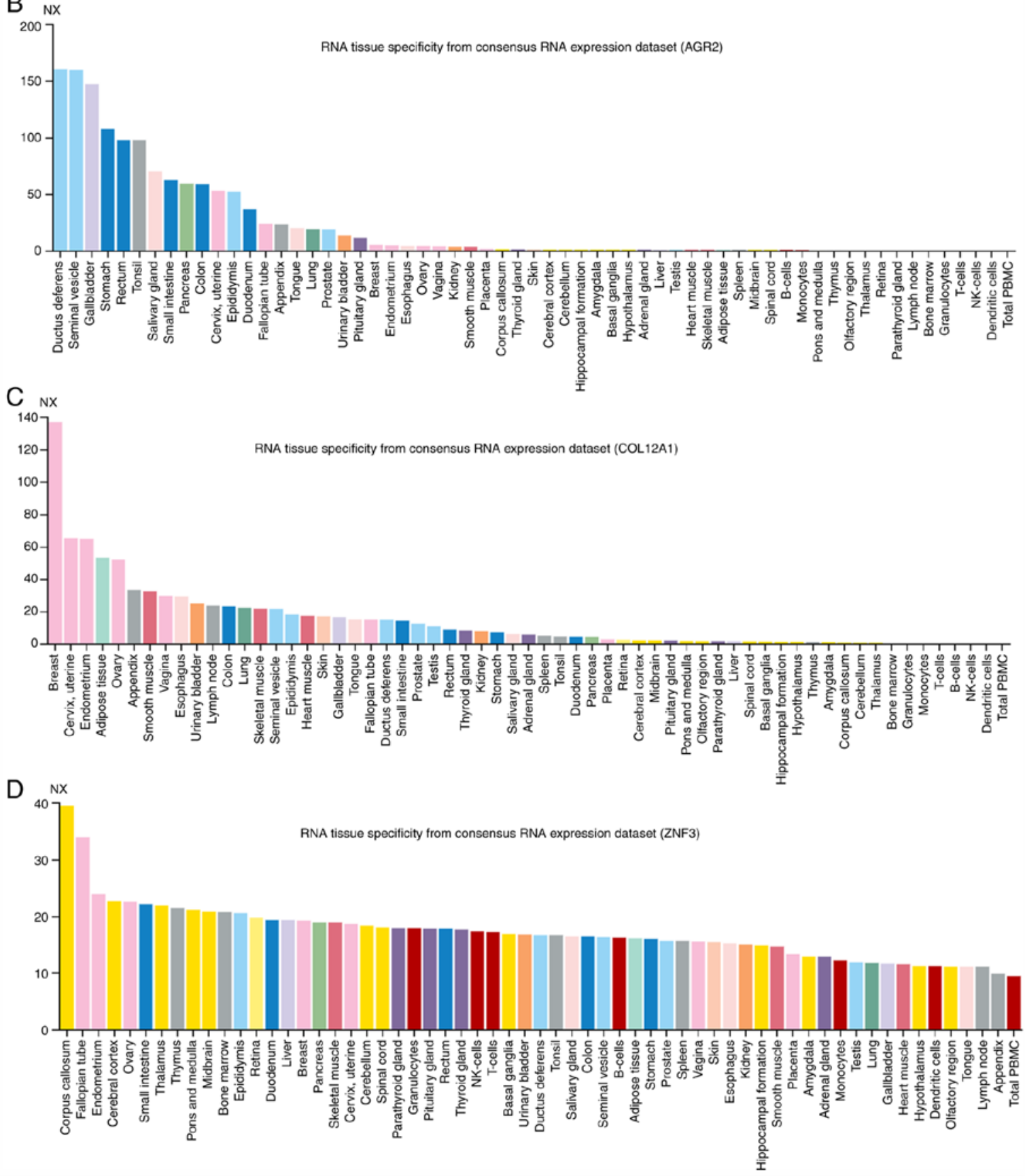

Figure 7. RNA tissue specificity analysis using the Tissue Atlas of the Human Protein Atlas. (A) ADAMTS1, (B) AGR2, (C) COL12A1 and (D) ZNF3. PBMC, peripheral blood mononuclear cells; NX, normalized expression which is computed using Trimmed Mean of M-values methods within the Human Protein Atlas; ADAMTS1, ADAM metallopeptidase with thrombospondin type 1 motif 1; AGR2, anterior gradient 2; COL12A1, collagen type XII $\alpha 1$ chain; ZNF3, Zinc finger protein 3. 
Receptor (PDB Id)

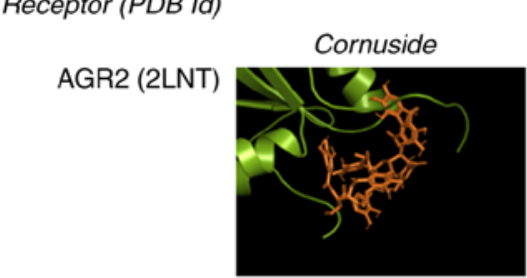

Docking score $=-8.1$

SRD5A2 (6OQX)

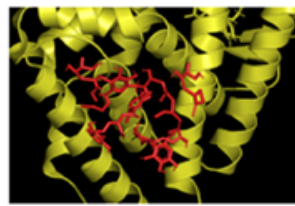

Docking score $=-9.5$

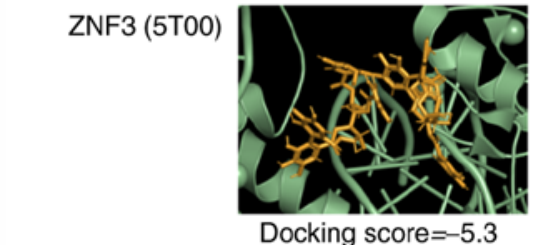

COL12A1 (1U5M)

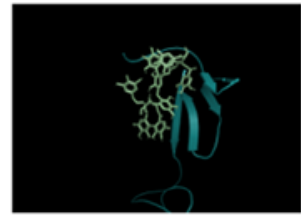

Docking score $=-6.9$
Ligands and the best docked complex

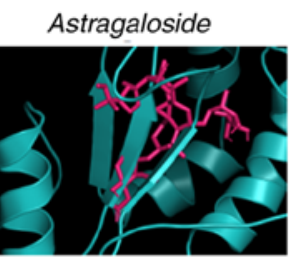

Docking score $=-6.9$

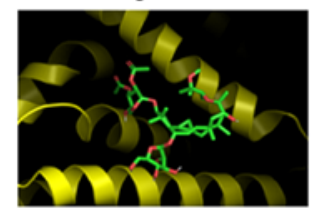

Docking score $=-7.6$

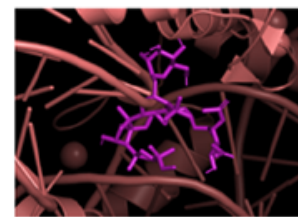

Docking score $=-6.5$

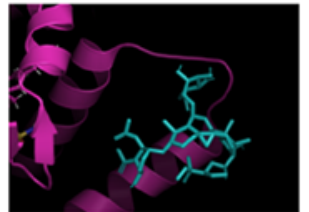

Docking score $=-6.1$
Berberine

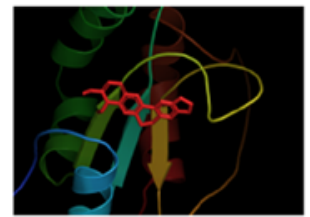

Docking score $=-6.8$

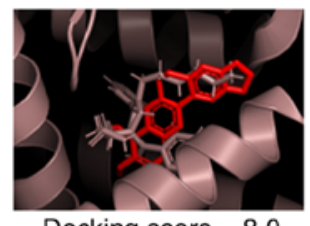

Docking score $=-8.0$

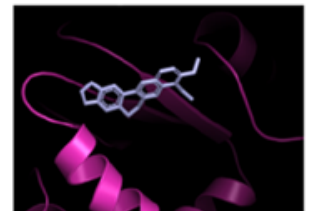

Docking score $=-6.1$

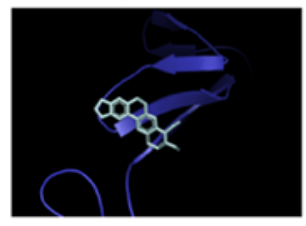

Docking score $=-6.4$
Cinnamonitride

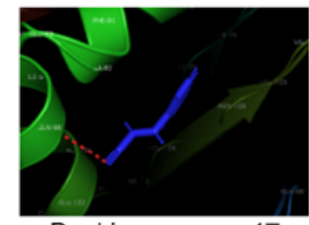

Docking score $=-47$

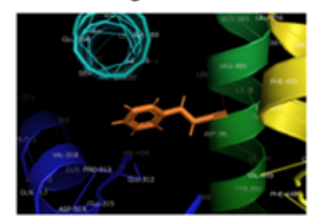

Docking score $=-5.4$

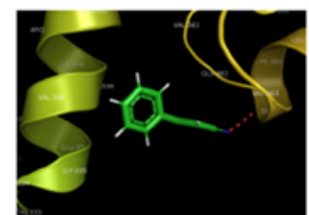

Docking score $=-5.0$

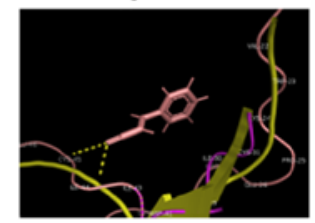

Docking score $=-4.1$

Figure 8. Best docked complexes with docking scores of receptors. AGR2 (2LNT), SRD5A2 (6OQX), ZNF3 (5T00), and COL12A1 (1U5M). PDB, protein databank; SRD5A, $5 \alpha$ reductase; AGR2, anterior gradient 2; COL12A1, collagen type XII $\alpha 1$ chain; ZNF3, Zinc finger protein 3.

A

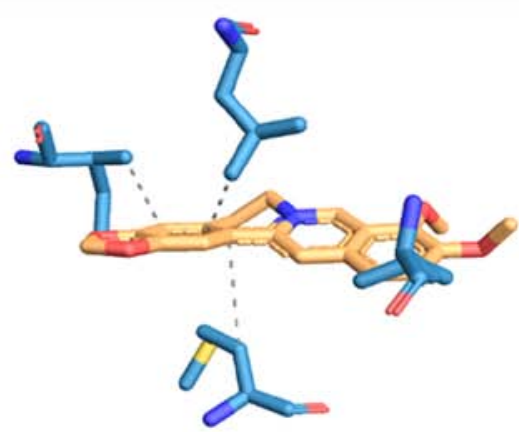

$60 Q \times$ to Berberine

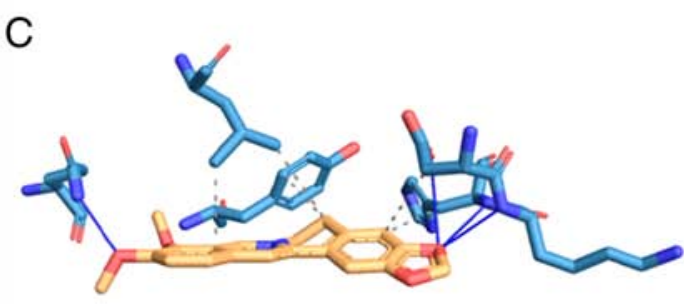

2LNT to Berberine
B

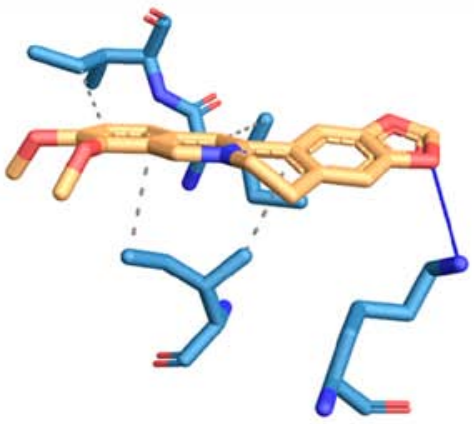

$1 \mathrm{U} 5 \mathrm{M}$ to Berberine
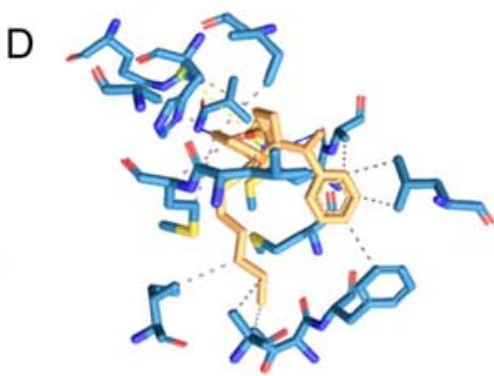

$5 \mathrm{~T} 00$ to Berberine
- Protein

i.

- Water

- Charge center

Aromatic ring center

- Metal ion

.... Hydrophobic interaction

- Hydrogen bond

- Water bridge

... $\pi$-Stacking (parallel)

$\cdots \cdot \pi$-Stacking (perpendicular)

$\cdots \cdot \pi$-Cation interaction

- Halogen bond

... Salt bridge

... Metal complexation

Figure 9. Interactions between berberine and the selected target receptor proteins. (A) 6OQX to Berberine, (B) 1U5M to Berberine, (C) 2LNT to Berberine, (D) $5 \mathrm{~T} 00$ to Berberine.

results suggest that the AGR2 receptor (2LNT) and berberine (Huang Bo) form a stable complex that maybe examined in further pharmacological studies. Further experimental studies are required to confirm the present computational results. 


\section{Acknowledgements}

Not applicable.

\section{Funding}

No funding was received.

\section{Availability of data and materials}

The datasets generated and/or analyzed during the current study are available in the NCBI-GEO repository (https://www. ncbi.nlm.nih.gov/geo/query/acc.cgi?acc=GSE6099).

\section{Authors' contributions}

MG conceived and designed the study; MG and ZC collected and analyzed the data for this study; ZC wrote the manuscript; and $\mathrm{MG}$ reviewed and edited the manuscript. All authors read and approved the final manuscript.

\section{Ethics approval and consent to participate}

Not applicable.

\section{Patient consent for publication}

Not applicable.

\section{Competing interests}

The authors declare that they have no competing interests.

\section{References}

1. Lorenzo G, Hughes TJR, Dominguez-Frojan P, Reali A and Gomez H: Computer simulations suggest that prostate enlargement due to benign prostatic hyperplasia mechanically impedes prostate cancer growth. Proc Natl Acad Sci USA 116: 1152-1161, 2019.

2. NIH-NIDDK. Prostate Enlargement (Benign Prostatic Hyperplasia)|NIDDK [Internet]. National Institute of Diabetes and Digestive and Kidney Diseases. 2019 [cited 2020 Jan 16]. Available from: https://www.niddk.nih.gov/health-information/ urologic-diseases/prostate-problems/prostate-enlargement-benignprostatic-hyperplasia.

3. Nicholson TM and Ricke WA: Androgens and estrogens in benign prostatic hyperplasia: Past, present and future. Differentiation 82 : 184-199, 2011.

4. Hata J, Satoh Y, Akaihata H, Hiraki H, Ogawa S, Haga N, Ishibashi K, Aikawa K and Kojima Y: Molecular classification of benign prostatic hyperplasia: A gene expression profiling study in a rat model. Int J Urol 23: 599-612, 2016.

5. Dai X, Fang X, Ma Y and Xianyu J: Benign prostatic hyperplasia and the risk of prostate cancer and bladder cancer: A meta-analysis of observational studies. Medicine (Baltimore) 95: e3493, 2016.

6. Miah S and Catto J: BPH and prostate cancer risk. Indian J Urol 30: 214-218, 2014.

7. Chughtai B, Forde JC, Thomas DD, Laor L, Hossack T, Woo HH, Te AE and Kaplan SA: Benign prostatic hyperplasia. Nat Rev Dis Primers 2: 16031, 2016.

8. Kim EH, Larson JA and Andriole GL: Management of benign prostatic hyperplasia. Annu Rev Med 67: 137-151, 2016.

9. Barry MJ, Fowler FJ, O'Leary MP, Bruskewitz RC, Holtgrewe HL and Mebust WK: Measuring disease-specific health status in men with benign prostatic hyperplasia. Measurement committee of the American urological association. Med Care 33 (Suppl 4): AS145-AS155, 1995.
10. Rawla P: Epidemiology of prostate cancer. World J Oncol 10: 63-89, 2019.

11. Levitt JM and Slawin KM: Prostate-specific antigen and prostate-specific antigen derivatives as predictors of benign prostatic hyperplasia progression. Curr Urol Rep 8: 269-274, 2007.

12. Nickel JC, Aaron L, Barkin J, Elterman D, Nachabé M and Zorn KC: Canadian urological association guideline on male lower urinary tract symptoms/benign prostatic hyperplasia (MLUTS/BPH): 2018 update. Can Urol Assoc J 12: 303-312, 2018.

13. Chen J, Zhang D, Yan W, Yang D and Shen B: Translational bioinformatics for diagnostic and prognostic prediction of prostate cancer in the next-generation sequencing era. Biomed Res Int 2013: 901578, 2013.

14. Mobley RE and Bizzarro MJ: Central line-associated bloodstream infections in the NICU: Successes and controversies in the quest for zero. Semin Perinatol 41: 166-174, 2017.

15. Tacklind J, Fink HA, Macdonald R, Rutks I and Wilt TJ: Finasteride for benign prostatic hyperplasia. Cochrane Database Syst Rev 6: CD006015, 2010.

16. Michel MC and Vrydag W: Alpha1-, alpha2- and beta-adrenoceptors in the urinary bladder, urethra and prostate. $\mathrm{Br} \mathrm{J}$ Pharmacol 147 (Suppl 2): S88-S119, 2006.

17. Yadav SS, Li J, Lavery HJ, Yadav KK and Tewari AK: Next-generation sequencing technology in prostate cancer diagnosis, prognosis, and personalized treatment. Urol Oncol 33: 267. e1-e13, 2015.

18. 18.Yu ZJ, Yan HL, Xu FH, Chao HC, Deng LH, Xu XD, Huang JB and Zeng T: Efficacy and side effects of drugs commonly used for the treatment of lower urinary tract symptoms associated with benign prostatic hyperplasia. Front Pharmacol 11: 658, 2020.

19. Davis S and Meltzer PS: GEOquery: A bridge between the gene expression omnibus (GEO) and BioConductor. Bioinformatics 23: 1846-1847, 2007.

20. Smyth GK: Limma: Linear models for microarray data. In: Gentleman R, Carey VJ, Huber W, Irizarry RA and Dudoit S (eds). Bioinformatics and Computational Biology Solutions Using $\mathrm{R}$ and Bioconductor. Statistics for Biology and Health, Springer, New York, NY, pp397-420, 2005.

21. Huang DW, Sherman BT and Lempicki RA: Bioinformatics enrichment tools: Paths toward the comprehensive functional analysis of large gene lists. Nucleic Acids Res 37: 1-13, 2009.

22. Warde-Farley D, Donaldson SL, Comes O, Zuberi K, Badrawi R, Chao P, Franz M, Grouios C, Kazi F, Lopes CT, et al: The GeneMANIA prediction server: Biological network integration for gene prioritization and predicting gene function. Nucleic Acids Res 38: W214-W220, 2010.

23. Uhlén M, Fagerberg L, Hallström BM, Lindskog C, Oksvold P, Mardinoglu A, Sivertsson Å, Kampf C, Sjöstedt E, Asplund A, et al: Proteomics. Tissue-based map of the human proteome. Science 347: 1260419, 2015.

24. Gaulton A, Bellis LJ, Bento AP, Chambers J, Davies M, Hersey A, Light Y, McGlinchey S, Michalovich D, Al-Lazikani B and Overington JP: ChEMBL: A large-scale bioactivity database for drug discovery. Nucleic Acids Res 40: D1100-D1107, 2012.

25. Kim S, Thiessen PA, Bolton EE, Chen J, Fu G, Gindulyte A, Han L, He J, He S, Shoemaker BA, et al: PubChem substance and compound databases. Nucleic Acids Res 44: D1202-D1213, 2016.

26. Wishart DS, Knox C, Guo AC, Cheng D, Shrivastava S, Tzur D, Gautam B and Hassanali M: DrugBank: A knowledgebase for drugs, drug actions and drug targets. Nucleic Acids Res 36: D901-D906, 2008.

27. Trott $\mathrm{O}$ and Olson AJ: AutoDock Vina: Improving the speed and accuracy of docking with a new scoring function, efficient optimization, and multithreading. J Comput Chem 31: 455-461, 2010.

28. Salentin S, Schreiber S, Haupt VJ, Adasme MF and Schroeder M: PLIP: Fully automated protein-ligand interaction profiler. Nucleic Acids Res 43: W443-W447, 2015.

29. Schena M, Shalon D, Davis RW and Brown PO: Quantitative monitoring of gene expression patterns with a complementary DNA microarray. Science 270: 467-470, 1995.

30. Draghici S. Data Analysis Tools for DNA Microarrays. Chapman and Hall/CRC Press, Boca Raton (FL), 2003. Available from: https://trove.nla.gov.au/version/46530985.

31. Raza K: Reconstruction, topological and gene ontology enrichment analysis of cancerous gene regulatory network modules. Curr Bioinform 11: 243-258, 2016.

32. Raza K and Hasan AN: A comprehensive evaluation of machine learning techniques for cancer class prediction based on microarray data. Int J Bioinform Res Appl 11: 397-416, 2015. 
33. Raza K: Analysis of microarray data using artificial intelligence based techniques. In: Handbook of Research on Computational Intelligence Applications in Bioinformatics, pp216-239, 2016.

34. Cross NA, Chandrasekharan S, Jokonya N, Fowles A, Hamdy FC, Buttle DJ and Eaton CL: The expression and regulation of ADAMTS-1, $-4,-5,-9$, and -15 , and TIMP-3 by TGFbeta 1 in prostate cells: Relevance to the accumulation of versican. Prostate 63: 269-275, 2005.

35. Burger MJ, Tebay MA, Keith PA, Samaratunga HM, Clements J, Lavin MF and Gardiner RA: Expression analysis of delta-catenin and prostate-specific membrane antigen: Their potential as diagnostic markers for prostate cancer. Int J Cancer 100: 228-237, 2002.

36. Cohen P, Peehl DM, Baker B, Liu F, Hintz RL and Rosenfeld RG Insulin-like growth factor axis abnormalities in prostatic stromal cells from patients with benign prostatic hyperplasia. J Clin Endocrinol Metab 79: 1410-1415, 1994.

37. Piñero J, Ramírez-Anguita JM, Saüch-Pitarch J, Ronzano F, Centeno E, Sanz F and Furlong LI: The DisGeNET knowledge platform for disease genomics: 2019 update. Nucleic Acids Res 48 : D845-D855, 2020.

38. Gustavsson H, Tesan T, Jennbacken K, Kuno K, Damber JE and Welén K: ADAMTS1 alters blood vessel morphology and TSP1 levels in LNCaP and LNCaP-19 prostate tumors. BMC Cancer 10: 288, 2010.

39. Chen Y, Wang J, Fraig MM, Metcalf J, Turner WR, Bissada NK Watson DK and Schweinfest CW: Defects of DNA mismatch repair in human prostate cancer. Cancer Res 61: 4112-4121, 2001.

40. Armenia J, Wankowicz SAM, Liu D, Gao J, Kundra R, Reznik E, Chatila WK, Chakravarty D, Han GC, Coleman I, et al: The long tail of oncogenic drivers in prostate cancer. Nat Genet 50 645-651, 2018

41. Morgenbesser SD, McLaren RP, Richards B, Zhang M, Akmaev VR, Winter SF, Mineva ND, Kaplan-Lefko PJ, Foster BA, Cook BP, et al: Identification of genes potentially involved in the acquisition of androgen-independent and metastatic tumor growth in an autochthonous genetically engineered mouse prostate cancer model. Prostate 67: 83-106, 2007.

42. Maresh EL, Mah V, Alavi M, Horvath S, Bagryanova L, Liebeskind ES, Knutzen LA, Zhou Y, Chia D, Liu AY and Goodglick L: Differential expression of anterior gradient gene AGR2 in prostate cancer. BMC Cancer 10: 680, 2010.

43. Bu H, Bormann S, Schäfer G, Horninger W, Massoner P, Neeb A, Lakshmanan VK, Maddalo D, Nestl A, Sültmann H, et al: The anterior gradient 2 (AGR2) gene is overexpressed in prostate cancer and may be useful as a urine sediment marker for prostate cancer detection. Prostate 71: 575-587, 2011.

44. Neeb A, Hefele S, Bormann S, Parson W, Adams F, Wolf P, Miernik A, Schoenthaler M, Kroenig M, Wilhelm K, et al: Splice variant transcripts of the anterior gradient 2 gene as a marker of prostate cancer. Oncotarget 5: 8681-8689, 2014.

45. Paschke L, Rucinski M, Ziolkowska A, Zemleduch T, Malendowicz W, Kwias Z and Malendowicz LK: ZFP91-a newly described gene potentially involved in prostate pathology. Pathol Oncol Res 20: 453-459, 2014

46. Jiang H, Zhang L, Liu J, Chen Z, Na R, Ding G, Zhang H and Ding Q: Knockdown of zinc finger protein X-linked inhibits prostate cancer cell proliferation and induces apoptosis by activating caspase-3 and caspase-9. Cancer Gene Ther 19: 684-689, 2012

47. Vanaja DK, Cheville JC, Iturria SJ and Young CY: Transcriptional silencing of zinc finger protein 185 identified by expression profiling is associated with prostate cancer progression. Cancer Res 63: 3877-3882, 2003.

48. Abildgaard MO, Borre M, Mortensen MM, Ulhøi BP, Tørring N Wild P, Kristensen H, Mansilla F, Ottosen PD, Dyrskjøt L, et al Downregulation of zinc finger protein 132 in prostate cancer is associated with aberrant promoter hypermethylation and poor prognosis. Int J Cancer 130: 885-895, 2012.

49. Jiao L, Li Y, Shen D, Xu C, Wang L, Huang G, Chen L, Yang Y, Yang C, Yu Y and Sun Y: The prostate cancer-up-regulated Myc-associated zinc-finger protein (MAZ) modulates proliferation and metastasis through reciprocal regulation of androgen receptor. Med Oncol 30: 570, 2013.

50. Rahman MT: Zinc and benign prostatic hyperplasia (BPH) \& prostate cancer (PCa) association. Med Res Arch 4: 1-16, 2016.

51. Dunn TA, Fedor HL, De Marzo AM and Luo J: Molecular profiling of indolent human prostate cancer: Tackling technical challenges to achieve high-fidelity genome-wide data. Asian J Androl 14: 385-392, 2012.
52. O'Malley KJ, Eisermann K, Pascal LE, Parwani AV, Majima T, Graham L, Hrebinko K, Acquafondata M, Stewart NA, Nelson JB, et al: Proteomic analysis of patient tissue reveals PSA protein in the stroma of benign prostatic hyperplasia. Prostate 74 892-900, 2014

53. Adeola HA, Calder B, Soares NC, Kaestner L, Blackburn JM and Zerbini LF: In silico verification and parallel reaction monitoring prevalidation of potential prostate cancer biomarkers. Future Oncol 12: 43-57, 2015

54. Sacca PA, Mazza ON, Scorticati C, Vitagliano G, Casas G and Calvo JC: Human periprostatic adipose tissue: Secretome from patients with prostate cancer or benign prostate hyperplasia. Cancer Genomics Proteomics 16: 29-58, 2019.

55. Hsing AW, Chen C, Chokkalingam AP, Gao YT, Dightman DA, Nguyen HT, Deng J, Cheng J, Sesterhenn IA, Mostofi FK, et al: Polymorphic markers in the SRD5A2 gene and prostate cancer risk: A population-based case-control study. Cancer Epidemiol Biomarkers Prev 10: 1077-102, 2001.

56. Choi SY, Kim HJ, Cheong HS and Myung SC: The association of 5 -alpha reductase type 2 (SRD5A2) gene polymorphisms with prostate cancer in a Korean population. Korean J Urol 56: 19-30, 2015.

57. Choubey VK, Sankhwar SN, Carlus SJ, Singh AN, Dalela D, Thangaraj K and Rajender S: SRD5A2 gene polymorphisms and the risk of benign prostatic hyperplasia but not prostate cancer. Asian Pac J Cancer Prev 16: 1033-1036, 2015.

58. Zeng XT, Su XJ, Li S, Weng H, Liu TZ and Wang XH: Association between SRD5A2 rs523349 and rs9282858 polymorphisms and risk of benign prostatic hyperplasia: A meta-analysis. Front Physiol 8: 688, 2017

59. Lodewijk L, Willems SM, Dreijerink KMA, de Keizer B, van Diest PJ, Schepers A, Morreau H, Bonenkamp HJ, Van Engen-van Grunsven IACH, Kruijff S, et al: The theranostic target prostate-specific membrane antigen is expressed in medullary thyroid cancer. Hum Pathol 81: 245-254, 2018.

60. Sácha P, Zámecník J, Barinka C, Hlouchová K, Vícha A, Mlcochová P, Hilgert I, Eckschlager T and Konvalinka J: Expression of glutamate carboxypeptidase II in human brain. Neuroscience 144: 1361-1372, 2007.

61. O'Keefe DS, Bacich DJ and Heston WD: Comparative analysis of prostate-specific membrane antigen (PSMA) versus a prostate-specific membrane antigen-like gene. Prostate 58: 200-210, 2004.

62. Kinoshita Y, Kuratsukuri K, Landas S, Imaida K, Rovito PM Jr, Wang CY and Haas GP: Expression of prostate-specific membrane antigen in normal and malignant human tissues. World J Surg 30: 628-636, 2006.

63. Kumar R, Verma V, Sarswat A, Maikhuri JP, Jain A, Jain RK, Sharma VL, Dalela D and Gupta G: Selective estrogen receptor modulators regulate stromal proliferation in human benign prostatic hyperplasia by multiple beneficial mechanisms-action of two new agents. Invest New Drugs 30: 582-593, 2012.

64. Huang DW, Sherman BT, Tan Q, Collins JR, Alvord WG, Roayaei J, Stephens R, Baseler MW, Lane HC and Lempicki RA: The DAVID gene functional classification tool: A novel biological module-centric algorithm to functionally analyze large gene lists. Genome Biol 8: R183, 2007.

65. Raza K: Protein features identification for machine learning-based prediction of protein-protein interactions. In: International Conference on Information, Communication and Computing Technology, pp305-317, 2017.

66. Raza K and Parveen R: Soft computing approach for modeling genetic regulatory networks. In: Advances in Computing and Information Technology. Advances in Intelligent Systems and Computing. Meghanathan N, Nagamalai D and Chaki N (eds). Springer, Berlin, Heidelberg, pp1-11, 2013

67. Raza K and Parveen R: Reconstruction of gene regulatory network of colon cancer using information theoretic approach. In: Confluence 2013: The Next Generation Information Technology Summit (4th International Conference), pp461-466, 2013.

68. Kryuchkova-Mostacci N and Robinson-Rechavi M: A benchmark of gene expression tissue-specificity metrics. Brief Bioinform 18: 205-214, 2017.

This work is licensed under a Creative Commons Attribution-NonCommercial-NoDerivatives 4.0 International (CC BY-NC-ND 4.0) License. 